\title{
Nitrogen Carrier Gas Flow for Reduced Steam Requirements of Water Splitting in a Packed Bed Hydrolysis Reactor
}

\author{
K. Pope ${ }^{1}$, G. F. Naterer ${ }^{2}$, Z. L. Wang ${ }^{3}$ \\ University of Ontario Institute of Technology \\ 2000 Simcoe Street North, Oshawa, Ontario, Canada, L1H 7K4 \\ ${ }^{1}$ kevin.pope@uoit.ca, ${ }^{2}$ greg.naterer@uoti.ca, ${ }^{3}$ forest.wang@uoit.ca
}

\begin{abstract}
This paper presents new experimental data and modeling of a copper (II) chloride $\left(\mathrm{CuCl}_{2}\right)$ hydrolysis reactor for thermochemical hydrogen production with the $\mathrm{Cu}-\mathrm{Cl}$ cycle. A hydrated nitrogen stream reacts with $\mathrm{CuCl}_{2}$ particles at various temperatures between $365^{\circ} \mathrm{C}$ and $400^{\circ} \mathrm{C}$ to investigate the reaction extent of steam in the endothermic reactor. Thermal decomposition of the solid reactant is examined by monitoring the chlorine production in the gaseous effluent. The theoretical maximum steam conversion is calculated from the Gibbs reaction energy and compared with the experimental results via the reaction quotient. The results of this paper provide significant new data to achieve higher conversion efficiencies of steam in the $\mathrm{Cu}-\mathrm{Cl}$ cycle than previously obtained in past experimental and predictive data.
\end{abstract}

\section{Nomenclature}

$D \quad$ diameter, $\mathrm{m}$

$f \quad$ fugacity, bar

G Gibbs free energy, $\mathrm{kJ} / \mathrm{mol}$

$R H$ relative humidity

$H$ enthalpy, $\mathrm{kJ} / \mathrm{mol}$

K constant

L bed depth, m

$M$ molarity, mol/L

$\boldsymbol{M}$ molar mass, $\mathrm{kg} / \mathrm{mol}$

$N \quad$ number of moles 


$\begin{array}{cl}p & \text { pressure, } \mathrm{Pa} \\ Q & \text { quotient } \\ t & \text { time, } \mathrm{s} \\ T & \text { temperature, }{ }^{\circ} \mathrm{C} \\ \forall & \text { volume, } \mathrm{L} \\ X & \text { fraction }\end{array}$

\section{Greek}

$\begin{array}{ll}\varepsilon & \text { void fraction } \\ \rho & \text { density, } \mathrm{kg} / \mathrm{m}^{3} \\ \mu & \text { viscosity, } \mathrm{Pa} \cdot \mathrm{s} \\ \xi & \text { steam requirement }\end{array}$

\section{Subscripts}

$\begin{array}{ll}e & \text { equilibrium } \\ f & \text { formation } \\ g & \text { gas } \\ H & \text { humidifier } \\ m f & \text { minimum fluidization } \\ p & \text { particle } \\ R & \text { reaction } \\ s & \text { solid } \\ T & \text { total }\end{array}$

\section{Superscript}

$\circ \quad$ reference condition

\section{Introduction}

In a past study for NHI (Nuclear Hydrogen Initiative; [1]), a comprehensive analysis of different thermochemical cycles for hydrogen production was performed. Lewis and Masin [1] 
reported that the $\mathrm{Cu}-\mathrm{Cl}$ cycle was a promising cycle due to its lower maximum temperature than other cycles, no catalyst required, and reactions going to completion with minimal side reactions. In past studies that evaluated thermochemical cycles for hydrogen production, Andress et al. [2] reported five critical areas of research. These include: (i) conceptualization, (ii) reaction cluster synthesis, (iii) flow sheet design, simulation, and analysis, (iv) process integration and (v) performance evaluation. Development of the $\mathrm{Cu}-\mathrm{Cl}$ cycle has previously completed the first three stages [3], with system integration of experimental unit operation still remaining. This paper presents new experimental results of key parameters related to the hydrolysis reactor's performance, for the reactor's integration with other system components of the $\mathrm{Cu}-\mathrm{Cl}$ cycle.

Past studies of the $\mathrm{Cu}-\mathrm{Cl}$ cycle $[4,5]$ have utilized three variations to split water into hydrogen and oxygen. The cycle forms a closed internal loop to continuously reuse all of the copper and chlorine compounds in the cycle, by transferring and recycling the chemicals between the three reactors. Development of each reactor in the cycle has achieved significant progress towards an integrated cycle $[4,5]$. However, recent studies have indicated that the hydrolysis reactor may impose a significant challenge for achieving high cycle efficiencies. In the hydrolysis reactor, steam is decomposed into hydrogen chloride and copper oxychloride by reacting with copper (II) chloride, i.e., $2 \mathrm{CuCl}_{(\mathrm{s})}+2 \mathrm{H}_{2} \mathrm{O}_{(\mathrm{g})}=\mathrm{Cu}_{2} \mathrm{OCl}_{2(\mathrm{~s})}+2 \mathrm{HCl}_{\text {(g) }}$ at $\approx 375^{\circ} \mathrm{C}$. However, nearly complete conversion of the solid reactant is necessary for the following downstream thermolysis reaction and high steam conversion is necessary for the operation of the electrolyzer [6]. Recent electrolyzer results indicate that a specific $\mathrm{HCl} / \mathrm{H}_{2} \mathrm{O}$ concentration of $6 \mathrm{M}$ to $11 \mathrm{M}[4,5,7]$ is needed for effective operation.

In past experiments with a hydrolysis spray reactor, the $\mathrm{H}_{2} \mathrm{O}$ and $\mathrm{CuCl}_{2}$ reactant was injected into the reactor as an aqueous solution, with argon as an inert carrier gas [8]. Using a pneumatic nebulizer, Ferrandon et al. [8] achieved a molar steam to copper chloride ratio of 21, based on X-ray diffraction (XRD) analysis of $\mathrm{CuCl}_{2}$ and $\mathrm{Cu}_{2} \mathrm{OCl}_{2}$ in the products. To achieve the desired quantities of $\mathrm{Cu}_{2} \mathrm{OCl}_{2}$ in the products, the argon gas flowrate was $400 \mathrm{~mL} / \mathrm{min}$ (at lower argon flowrates, insufficient $\mathrm{Cu}_{2} \mathrm{OCl}_{2}$ is produced to be identified by XRD analysis). Ferrandon et al. [8] have shown that higher flowrates cause smaller droplet sizes which enhance the reaction by increasing the surface area of the droplets. 
During hydrolysis spray reactor experiments with an ultrasonic nozzle, Ferrandon et al. [9] injected a mixture of argon and aqueous $\mathrm{CuCl}_{2}$ into the reactor. The authors found that a steam to copper chloride ratio of 20 produced the highest yield of desired products, with higher or lower ratios increasing both $\mathrm{CuCl}_{2}$ and/or $\mathrm{CuCl}$ in the reactants. When the system pressure was reduced

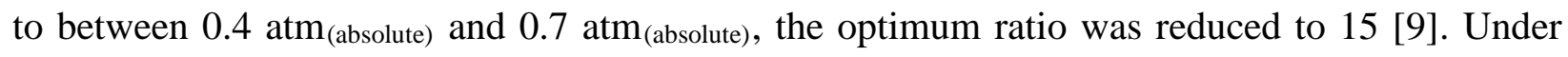
these conditions, an undesirable product, $\mathrm{Cl}_{2}$, was significantly reduced due to the large steam-tocupric chloride ratios, which influence both the reaction equilibrium and kinetics. By studying the reaction kinetics, Daggupati et al. [10] modeled data at $350^{\circ} \mathrm{C}$ and $400^{\circ} \mathrm{C}$, where complete conversion of the solid reactant can be achieved with a steam to copper chloride ratio of 40 (mol) and 28 (mol), respectively.

Reducing the steam requirement and undesirable production of $\mathrm{Cl}_{2}$ of the hydrolysis reactor is a key parameter to achieve higher cycle efficiency. If the gaseous $\mathrm{HCl} / \mathrm{H}_{2} \mathrm{O}$ mixture exiting the hydrolysis reactor is below the requirements of the electrolyzer, an energy intensive concentration process is required, which will significant reduce the efficiency of the $\mathrm{Cu}-\mathrm{Cl}$ cycle. In this paper, the focus is to present new experimental results to reduce the steam requirements of the hydrolysis reactor by investigating the steam conversion efficiency, reaction quotient and chemical equilibrium. Since there exists the side reaction leading to the undesirable production of $\mathrm{Cl}_{2}$, preliminary reaction kinetic data will be reported in this paper to examine the influence on the equilibrium steam requirement.

\section{Formulation of reaction quotient and equilibrium constant}

In this section, the reaction quotient for a $\mathrm{CuCl}_{2}$ hydrolysis reactor, based on the molar flows of the gaseous stream, is presented. The hydrolysis reaction is represented as:

$$
2 \mathrm{CuCl}_{2(\mathrm{~s})}+\mathrm{H}_{2} \mathrm{O}_{(\mathrm{g})}=\mathrm{Cu}_{2} \mathrm{OCl}_{2(\mathrm{~s})}+2 \mathrm{HCl}_{(\mathrm{g})}
$$

where $\mathrm{HCl}$ product is condensed and sent to a downstream electrolyzer for hydrogen production in the $\mathrm{Cu}-\mathrm{Cl}$ cycle. Copper oxychloride $\left(\mathrm{Cu}_{2} \mathrm{OCl}_{2}\right)$ product is moved to a downstream thermolysis reactor for oxygen production. The Gibbs free energy of the reaction is represented by the 
difference in Gibbs free energy of formation of the products ( $\Delta G_{f, p r o d u c t s}^{\circ}$ ) and reactants $\left(\Delta G_{f, \text { reactants }}^{\circ}\right)$ :

$$
\Delta G_{R}^{\circ}=\Delta G_{f, \text { products }}^{\circ}-\Delta G_{f, \text { reactants }}^{\circ}
$$

where the superscript “o” means the standard state.

Calculated values of $\Delta H_{f}^{\circ}(T)$ and $\Delta S_{f}^{\circ}(T)$ yield the Gibbs formation free energy at various temperatures.

$$
\Delta G_{f}^{\circ}(T)=\Delta H_{f}^{\circ}(T)-T \Delta S_{f}^{\circ}(T)
$$

Equation (3) predicts $\Delta G_{f}^{\circ}$ at various operating temperatures of a copper (II) chloride hydrolysis reactor. The equilibrium constant of the reaction $\left(K_{e}\right)$ can be obtained from the Gibbs free energy of the reaction as follows,

$$
K_{e}=\exp \left(-\frac{\Delta G_{R}^{\circ}}{R T}\right)
$$

This equilibrium constant provides key information for integrating the hydrolysis reactor with the $\mathrm{CuCl} / \mathrm{HCl}$ electrolyzer, reducing the steam requirement of the reactor, and improving the $\mathrm{Cu}-\mathrm{Cl}$ cycle efficiency.

The reaction quotient $\left(\mathrm{Q}_{\mathrm{R}}\right)$ represents the extent of reaction with respect to its chemical equilibrium, such that $K_{e}$ and $Q_{R}$ will be in unity when the reaction reaches equilibrium. The reaction quotient is represented in terms of the relative fugacities of the constituents [11]:

$$
Q_{R}=\left[\frac{f_{\mathrm{CuOCuCl}_{2}} f_{\mathrm{HCl}}^{2}}{f_{\mathrm{CuCl}_{2}}^{2} f_{\mathrm{H}_{2} \mathrm{O}}}\right]
$$

From Eq. (1), the $\mathrm{Cu}_{2} \mathrm{OCl}_{2}$ and $\mathrm{CuCl}_{2}$ compounds remain solid during the reaction. For a solid, pressure variations have a negligible effect on fugacity, allowing $f_{\mathrm{CuCl}_{2}}^{2}$ and $f_{\mathrm{CuOCuCl}_{2}}$ to be estimated as unity. At low pressures of ambient conditions, the gases are assumed as ideal gases, so the difference between the gaseous compound fugacities and partial pressures are negligible, i.e., $f \approx p$, reducing Eq. (5) as follows, 
$Q_{R}=\left(\frac{p_{H C l}^{2}}{p_{H_{2} O}}\right)$

The partial pressure of the gaseous compounds can be represented in terms of the molar fraction as follows:

$$
p_{H C l}=\frac{N_{H C l}}{N_{T}} p_{T}
$$

and

$$
p_{H_{2} O}=\frac{N_{H_{2} O} O}{N_{T}} p_{T}
$$

where $\mathrm{N}_{\mathrm{T}}$ represents the total number of moles in the reactor. If an inert gas is present, then $N_{T}$ can be represented by $N_{T}=N_{H C l}+N_{H 2 O}+N_{i}$, where $N_{i}$ represents the number of gaseous moles not participating in the reaction (e.g. an inert carrier gas). Substituting Eqs. (7) and (8) into Eq. (6) and rearranging yields

$$
Q_{R}=\frac{N_{H C l}^{2}}{N_{H_{2} \mathrm{O}}}\left(\frac{p_{T}}{N_{H C l}+N_{H 2 O}+N_{i}}\right)
$$

These expressions will be used to minimize the steam requirements of the hydrolysis reactor.

As presented in Eq. (4), an effective method to approach the equilibrium is to significantly increase the residence time of $\mathrm{CuCl}_{2}$ and $\mathrm{H}_{2} \mathrm{O}$, to provide a longer contact time between the two reactants. However, there also exists a side reaction which produces chlorine from $\mathrm{CuCl}_{2}$ thermal decomposition, i.e., $\mathrm{CuCl}_{2(\mathrm{~s})}=\mathrm{CuCl}_{(\mathrm{s})}+0.5 \mathrm{Cl}_{2(\mathrm{~g})}$, which is increased with longer residence times. Chlorine gas production will affect the quantity of desirable products, $\mathrm{HCl}$ and $\mathrm{Cu}_{2} \mathrm{OCl}_{2}$, due to the undesirable decomposition of $\mathrm{CuCl}_{2}$ (although the equilibrium constant is unaltered by the formation of $\mathrm{Cl}_{2}$ ). This paper will also present new experimental results on $\mathrm{Cl}_{2}$ formation kinetics from $\mathrm{CuCl}_{2}$ decomposition. 


\section{Experimental hydrolysis reactor with humidified nitrogen}

The experimental apparatus consists of a packed bed reactor and a humidifier operating at ambient temperature. As illustrated in Fig. 1, the experimental setup includes a series of components to prepare the gaseous reactant before entering the reactor. Nitrogen flows through a number of flow control valves, as well as pressure and temperature sensors before entering the humidifier system.

The hydrator piping is half filled with distilled water, which partially saturates the nitrogen as it flows through the heated hydrator piping and over the distilled water. This design effectively delivers a low flow and precisely controlled steam flow rate and fraction, while enhancing the mixing of gas and solid reactants because of the additional nitrogen carrier gas. The nitrogen flow rate is controlled by two flow control valves, with ranges of 0 to 2 LPM and 0 to 50 LPM, respectively. The temperatures and pressures are measured before entering the hydrator, so the molar flow rate of $\mathrm{N}_{2}$ is determined as

$$
\dot{N}_{N_{2}}=\frac{\rho_{N_{2}} \times \dot{V}_{N_{2}}}{\boldsymbol{M}_{N_{2}}}
$$

A humidity sensor is positioned after the humidifier to measure the molar flow rate of $\mathrm{H}_{2} \mathrm{O}$ in the

reaction stream, $\dot{\mathrm{N}}_{\mathrm{H}_{2} \mathrm{O}, \mathrm{in}}$, which can be calculated from the nitrogen flow rate, temperature and relative humidity, as follows,

$$
\dot{N}_{\mathrm{H}_{2} \mathrm{O}, \text { in }}=\frac{\rho_{\mathrm{H}_{2} \mathrm{O}} \times \dot{\mathrm{V}}_{\mathrm{N}_{2}}}{\boldsymbol{M}_{\mathrm{H}_{2} \mathrm{O}}}
$$

The density of $\mathrm{H}_{2} \mathrm{O}\left(\rho_{\mathrm{H}_{2} \mathrm{O}}\right)$ in the flow is then calculated from the measured humidity and nitrogen flow rate as follows [12],

$$
\rho_{\mathrm{H}_{2} \mathrm{O}}=0.0022 \times \frac{\left(p_{s a t_{, \mathrm{H}_{2} \mathrm{O}}} / 100\right) \times R H_{H}}{\mathrm{~T}_{\mathrm{H}}}
$$

where $R H_{H}$ and $\mathrm{T}_{\mathrm{H}}$ represent the relative humidity and temperature of the steam exiting the humidifier. The partial pressure of $\mathrm{H}_{2} \mathrm{O}\left(p_{\mathrm{H}_{2} \mathrm{O}}\right)$ is determined by [12]:

$$
p_{\mathrm{H}_{2} \mathrm{O}}=R H \times p_{{\text {sat } \mathrm{H}_{2} \mathrm{O}}}=R H \times \exp \left(77.345+0.0057 \times\left(\mathrm{T}_{\mathrm{H}}\right)-\frac{7235}{\mathrm{~T}_{\mathrm{H}}^{8.2}}\right)
$$

A secondary flow path is included in the experimental design which allows isolation of the hydrator, bypassing directly to the reactor, thus allowing for purging and preheating, without introducing steam. 
The undesirable decomposition of $\mathrm{CuCl}_{2}$ may release $\mathrm{Cl}_{2}$, and will contribute to chloride formation in the gaseous product (in addition to a chloride contribution from the desirable product of $\mathrm{HCl}$ ). Thus, after leaving the reactor vessel, the flow is directed through a chlorine meter to determine the fraction of chlorine $\left(X_{C l_{2}}\right)$ in the fluid stream, allowing the flow rate of chlorine to be determined by

$$
\dot{N}_{C l_{2}}=\frac{X_{C l_{2}} \times \dot{N}_{N_{2}}}{1-\dot{X}_{C l_{2}}}
$$

Subsequently, the flow passes through a scrubber, which contains distilled water and sodium hydroxide $(\mathrm{NaOH})$ solution that reacts with the product fluid stream, to produce sodium chloride $(\mathrm{NaCl})$.

$$
N_{C l}=N_{N a C l}=N_{H C l}
$$

The chloride concentration of the scrubber solution is measured from the samples, at periodic intervals, during the reactor operation.

The total copper presence in the effluent stream is measured by an HACH copper colorimeter II. The total copper is equated with $\mathrm{CuCl}$ and $\mathrm{CuCl}_{2}$ to estimate the amount of entrained solid in the gaseous stream. The concentration of $\mathrm{HCl}$ is determined by the chloride concentration of samples from the scrubber solution, considering any chlorine production and entrainment, which also reacts with $\mathrm{NaOH}$. The flow rate of $\mathrm{HCl}\left(\dot{N}_{H C l, o u t}\right)$ out of the reactor is determined from Eqs. (1), (14), and (15), as follows,

$$
\dot{N}_{H C l, \text { out }}=\frac{\left(M_{H C l}\right)\left(V_{\text {scrubber }}\right)}{\Delta t}-2 \dot{N}_{C l_{2}}-2 \dot{N}_{C_{u C l}}
$$

where $\Delta t$ represents the time between each sample from the scrubber solution.

To determine the fluid flow regime in the reactor, the predicted minimum fluidization velocity $\left(\mathrm{V}_{\mathrm{mf}}\right)$ is compared with the measured velocity. If the flow condition is below or above the minimum fluidization velocity, then the fluid flow in the reactor can be represented by a packed or fluidization regime, respectively. The minimum fluidization velocity can be represented by [13]:

$$
V_{m f}=\frac{D_{p}^{2}\left(\rho_{s}-\rho_{v}\right) g}{150 \mu} \frac{\varepsilon_{m f} \Phi_{s}^{2}}{1-\varepsilon_{m f}}
$$


where $D_{p}, \rho_{s}, \rho_{v}, g, \mu, \varepsilon_{m f}$, and $\Phi_{s}$ represent the particle diameter, solid density, vapour density, gravitational acceleration, gaseous viscosity, void fraction (at minimum fluidization velocity), and sphericity, respectively.

\section{Results and discussion}

In this section, the predicted and experimental results of the packed bed reactor with humidified nitrogen are examined with respect to the steam conversion efficiency and thermodynamic equilibrium. Four separate experiments are performed with the experimental reactor. As shown in Table 1, each experiment is performed at a constant temperature, particularly, $400^{\circ} \mathrm{C}, 365^{\circ} \mathrm{C}$, and $390^{\circ} \mathrm{C}$ (two experiments), with the reaction maintained for 30 minutes to 2 hours for the various experiments. The reaction temperature is obtained from a thermocouple located in the gas stream directly before the perforated plate which holds the $\mathrm{CuCl}_{2}$ reactant. After each experiment, the reactor is purged with nitrogen, and then left to cool overnight before the solid product is removed in the following morning. Immediately after the solid product is removed, it is placed in a closed glove box with a nitrogen flow, where the containers are purged of air before they are sealed for XRD testing. In the first three experiments, $100 \mathrm{~g}$ of $\mathrm{CuCl}_{2}$ is placed in the reactor vessel, and increased to $450 \mathrm{~g}$ in the final experiment (Test 4), which aims to validate the results of Test 3.

At the end of each test, the scrubber solution is tested for the presence of copper $(\mathrm{Cu})$ and iron $(\mathrm{Fe})$. The amounts were found to be negligible for both elements. The absence of copper in the scrubber solution suggests that solid entrainment was negligible, so $\mathrm{CuCl}_{2}, \mathrm{CuCl}$, and $\mathrm{Cu}_{2} \mathrm{OCl}_{2}$ do not contribute to the presence of chlorides in the results. No iron in the scrubber solution suggests that iron-chloride compounds, such as $\mathrm{FeCl}_{3}$, from reactions with the vessel walls, do not contribute to the chloride concentration. The results of each experiment will be presented in detail before the results are combined for a further analysis. In all experiments in this section, the fluid velocity is maintained below $0.1 \mathrm{~m} / \mathrm{s}$. The minimum fluidization velocity, as predicted by Eq. (17), is $0.5 \mathrm{~m} / \mathrm{s}$, thus the flow can be represented by the packed bed regime. The parameters to calculate the minimum fluidization velocity are presented in Table 2.

\section{Experiment $1\left(400^{\circ} \mathrm{C}\right)$}


In the first experiment, the 3 thermocouples in the reactor reach equilibrium at $300^{\circ} \mathrm{C}$, before the temperature is increased to the reaction temperature. The dashed lines in Fig. 2 represent the start and end of $\mathrm{H}_{2} \mathrm{O}$ flow through the reactor (i.e., when the humidifier bypass is turned off and on, respectively), with $\mathrm{H}_{2} \mathrm{O}$ flow initiated at $258 \mathrm{~min}$. Immediately before changing the position of the bypass valves to allow flow through the humidifier, the reactor's effluent is directed away from the chlorine meter to the $\mathrm{NaOH}$ scrubber. After changing the position of the bypass valves to stop flow through the humidifier, the reactor's effluent is directed away from the $\mathrm{NaOH}$ scrubber to the chlorine meter. The chlorine detected between the two dashed lines (during the reaction) occurs from the residual nitrogen / chlorine mixture in the chlorine meter piping. It does not represent the chlorine produced during the reaction. As illustrated in Fig. 2b, chlorine fraction is measured and recorded every $1.6 \mathrm{~s}$, however, the chorine fraction is presented every 10 minutes with error bars representing the variability in the measurements.

As illustrated in Fig. 2b, the chlorine production increases dramatically as the reactor temperature reaches $400^{\circ} \mathrm{C}$. This dramatic rise in temperature indicates that $400^{\circ} \mathrm{C}$ is slightly above the optimum reaction temperature, which should be below the point of significant $\mathrm{Cl}_{2}$ production. The average chlorine production during the five minutes is taken before initiating steam flow. This predicts a chlorine production rate of $2.3 \%$ (volume) in the gaseous effluent. As illustrated in Fig. 3 , the solid product is a fine powder. The colour is relatively consistent, dark brown, throughout the sample. The sample was taken from the center of the solid product in the reactor, although the appearance of the products was homogenous throughout the solid.

In Fig. 4, an XRD (X-ray diffraction) result of the solid sample is presented. The presence of various compounds of $\mathrm{Mg}$, Fe and $\mathrm{Al}$-related chlorides, oxides and hydroxides was investigated, with no matches. Strong evidence of $\mathrm{CuCl}$ is exhibited, with minor constituent of $\mathrm{CuCl}_{2}$. The significant XRD results of solids of the hydrolysis reactor connected to an ambient humidifier are presented in Table 3. In Table 3, the hydrolysis reaction at $400^{\circ} \mathrm{C}$ decomposed the majority of the solids into $\mathrm{CuCl}$. Care was taken to limit solid decomposition during preheating.

In Fig. 5, the steam requirement is presented for the reaction temperature of $400^{\circ} \mathrm{C}$, comparing two chlorine percentages in a cumulative plot with respect to time. The time is taken to be 0 at the start of the reaction (i.e., at 258 minutes). The measurements of the chlorine meter suggest that the maximum volume of chlorine is $2.3 \%$. Assuming a chlorine fraction of 0.023 
during the reaction results in more chlorides in the scrubber solution from the chlorine presence than the total amount of chlorides measured in the scrubber (i.e., second term in Eq. (16) is larger than the first term). The maximum amount of $\mathrm{Cl}_{2}$ that can be assumed present during the reaction is $1.1 \%$. In Fig. 5, the data points for $\mathrm{Cl}_{2}=1 \%$ are omitted before 20 minutes, because they are negative (not physically possible).

\section{Experiment $2\left(365^{\circ} \mathrm{C}\right)$}

In the second experiment, the 3 thermocouples in the reactor are allowed to reach equilibrium at $200^{\circ} \mathrm{C}$, before the temperature is increased to the reaction temperature. The dashed lines represent the start and end of $\mathrm{H}_{2} \mathrm{O}$ flow through the reactor, with $\mathrm{H}_{2} \mathrm{O}$ flow initiated at 125 min. Before changing the position of the bypass valves, the reactor's effluent is directed away from and towards the chlorine meter and $\mathrm{NaOH}$ scrubber.

As illustrated in Fig. 6, chlorine is produced when the temperature increases above $200^{\circ} \mathrm{C}$, rising to a maximum of $0.23 \%$, before initiating the $\mathrm{H}_{2} \mathrm{O}$ flow, and directing the reactor effluent away from the chlorine meter. Taking the average chlorine production during the five minutes before initiating $\mathrm{H}_{2} \mathrm{O}$ flow yields a chlorine production rate of $0.198 \%$ (volume) in the gaseous effluent. After the reaction is stopped, the effluent is directed through the chlorine meter (second vertically dashed line in Fig. 6). The chlorine volume drops from 0.15 in the residual effluent, to 0.1 after the reaction. During the reaction, the chlorine production rate was reduced, possibly due to a surface film of $\mathrm{Cu}_{2} \mathrm{OCl}_{2}$ on the reactant surface. The transient molar flowrates of the gaseous compounds in the hydrolysis reactor at $365^{\circ} \mathrm{C}$ are presented in Fig. 7.

The $\mathrm{Cl}_{2}$ percentage, presented in Fig. 6, is significantly lower than in Fig. 2. This is explained by the reduced decomposition kinetics of $\mathrm{CuCl}_{2}$ at the lower temperature $\left(365^{\circ} \mathrm{C}\right)$ of the experiments in Fig. 6, compared to higher temperature $\left(400^{\circ} \mathrm{C}\right)$ in Fig. 2. These results suggest that temperature plays a vital role in the formation kinetics of $\mathrm{Cl}_{2}$, however, determining the limiting steps of $\mathrm{Cl}_{2}$ and hydrolysis kinetics requires further investigations.

Figure 8 illustrates the solid product from the hydrolysis reaction at $365^{\circ} \mathrm{C}$. The sample is a fine powder. The colour is relatively consistent, light brown, throughout the sample. The sample 
was taken from the center of the solid product in the reactor. The appearance of the products was homogenous throughout the solid.

In Fig 9, an XRD (X-ray diffraction) result of the solid sample, from the reaction at $365^{\circ} \mathrm{C}$, is presented. The presence of various compounds of Mg, Fe and Al-related chlorides, oxides and hydroxides was investigated, with no matches. Strong evidence of $\mathrm{CuCl}_{2}$ and $\mathrm{CuCl}$ are exhibited, with minor constituent of $\mathrm{Cu}_{2} \mathrm{OCl}_{2}$. As presented in Table 3, the hydrolysis reaction at $365^{\circ} \mathrm{C}$ showed evidence of some decomposition into $\mathrm{CuCl}$, with other reactants remaining as $\mathrm{CuCl}_{2}$.

In Fig. 10, the cumulative flow of nitrogen and steam into the reactor, and chlorine and hydrogen chloride flow out of the reactor, are presented. The volume flow of chlorine is assumed to be $0.1 \%$. The variations in the slope of the molar flows follow changes in the nitrogen flowrate. As presented in Eqs. (11) and (14), they are directly coupled with the nitrogen flowrate. The $\mathrm{HCl}$ production rates are taken from measured samples of the $\mathrm{NaOH}$ scrubber solution.

In Fig. 11, the steam requirement is presented for the reaction temperature of $365^{\circ} \mathrm{C}$, comparing three chlorine percentages in a cumulative plot with respect to time. The measurements of the chlorine meter suggest that the maximum volume of chlorine is $0.2 \%$, which can be considered the maximum possible chlorine present in the reactor. The three chlorine percentages are $0.2 \%, 0.1 \%$ and $0 \%$. In Fig. 11, the data point for $\mathrm{Cl}_{2}=0.2 \%$ is omitted at 25 minutes, because it is above the view of the plot, at an excess steam ratio of 24.

\section{Experiment $3\left(390^{\circ} \mathrm{C}\right)$}

In the third experiment, the 3 thermocouples in the reactor are allowed to reach equilibrium at $260^{\circ} \mathrm{C}$ before the temperature is increased to the reaction temperature. The dashed lines represent the start and end of $\mathrm{H}_{2} \mathrm{O}$ flow through the reactor, with $\mathrm{H}_{2} \mathrm{O}$ flow initiated at 119 min. Immediately before changing the position of the bypass valves, the reactor's effluent is directed away from and towards the chlorine meter and $\mathrm{NaOH}$ scrubber.

As shown in Fig. 12, chlorine is produced when the temperature increases above $200^{\circ} \mathrm{C}$, rising to a maximum of $0.35 \%$, before initiating the $\mathrm{H}_{2} \mathrm{O}$ flow, and directing the reactor effluent away from the chlorine meter. Using the average chlorine production during the five minutes 
before initiating $\mathrm{H}_{2} \mathrm{O}$ flow yields a chlorine production rate of $0.18 \%$ (volume) in the gaseous effluent. The large variation between the chlorine percentage before initiating the $\mathrm{H}_{2} \mathrm{O}$ flow and the 5 minutes average is caused by the sudden rise in chlorine production immediately before the start of the reaction. During the reaction, the chlorine volume in the residual effluent in the chlorine meter tubing rises to above $0.55 \%$, suggesting that the difference between the chlorine volume at the reaction start, $0.35 \%$, and the residual effluent during the reaction $(0.55 \%)$ is caused by starting the reaction as the product temperature is still rising. This limits the ability to obtain accurate predictions of the reactant decomposition, but also reduces the reactant decomposition which helps to provide more reliable results. After the reaction is stopped, the effluent is directed through the chlorine meter (second dashed line in Fig. 12). The chlorine volume drops from 0.55 in the residual effluent to 0.3 after the reaction, then continues to increase up to 0.55 . This result suggests that during the reaction, the chlorine production rate was suppressed from 0.55 to 0.3 .

As illustrated in Fig. 13, the molar flowrates of nitrogen, chlorine and steam out of the reactor follow similar trends during the hydrolysis reaction. The fluctuations at the start of the reaction are caused by changing valves to redirect the flow through the humidifier. The solid product, illustrated in Fig. 14, showed two different colour particles, consisting of light and dark brown, and irregularly shaped. XRD diffraction patterns of the sample, illustrated in Fig. 15, provide evidence that $\mathrm{CuCl}$ is the primary component of the mixture, with minor components of $\mathrm{CuCl}_{2}$ and $\mathrm{Cu}_{2} \mathrm{OCl}_{2}$.

In Fig 15, an XRD pattern of the solid sample, from the reaction at $390^{\circ} \mathrm{C}$, is presented, with samples taken from two locations in the reactor solids: one from each of the reactant's top and bottom surfaces, respectively. Strong evidence of $\mathrm{CuCl}_{2}$ is found in both samples, with significant $\mathrm{CuCl}$ in the bottom portion of the solids (i.e., near the distributor). In both samples, $\mathrm{Cu}_{2} \mathrm{OCl}_{2}$ is a minor constituent.

In Fig. 16, the cumulative flow of nitrogen and steam into the reactor, and chlorine and hydrogen chloride flow out of the reactor, are presented. The volume flow portion of chlorine is assumed to be $0.5 \%$. The $\mathrm{HCl}$ production is taken from measured samples of the $\mathrm{NaOH}$ scrubber solution. 
In Fig. 17, the steam requirement is presented for the reaction temperature of $390^{\circ} \mathrm{C}$, comparing three chlorine percentages in a cumulative plot with respect to time. The time is taken to be 0 at the start of the reaction. The measurements of the chlorine meter suggest that the maximum volume portion of chlorine is $0.182 \%$, which is the maximum possible chlorine present in the reactor. The three chlorine percentages are $0.5 \%, 0.18 \%$ and $0 \%$. In Fig. 17, all three assumptions for the volume of chlorine production produce a steam requirement that drops to near stoichiometric conversion of $\mathrm{H}_{2} \mathrm{O}$ at 30 minutes into the reaction.

\section{Experiment $4\left(390^{\circ} \mathrm{C}\right.$ - Validation $)$}

In the fourth experiment, the 3 thermocouples in the reactor were allowed to reach equilibrium at $300^{\circ} \mathrm{C}$, before the temperature was increased to the reaction temperature. $\mathrm{The}_{2} \mathrm{O}$ flow through the reactor was initiated at 209 min. In Experiment 4, the chlorine production was assumed to be $0.5 \%$ (Fig. 18).

In Fig. 19, the cumulative flow of nitrogen and steam into the reactor, and chlorine and hydrogen chloride flow out of the reactor, are presented. The volume flow portion of chlorine is assumed to be $0.5 \%$. The $\mathrm{HCl}$ production is taken from measured samples of the $\mathrm{NaOH}$ scrubber solution.

Validation of the steam requirement, for the reaction temperature of $390^{\circ} \mathrm{C}$, is presented in Fig. 20. The three chlorine percentages are $0.5 \%, 0.18 \%$ and $0 \%$. All three assumptions for the volume of chlorine production produce a steam requirement that drops to near stoichiometric conversion of steam at 80 minutes into the reaction. This plot exhibits good agreement with the results of Experiment 3, and provides useful validation of the results at $390^{\circ} \mathrm{C}$ with humidified nitrogen. These results are very promising because they demonstrate much lower steam to copper chloride ratios than previously reported in past literature [8-10]. As a result, they can lead to significantly higher efficiencies of the $\mathrm{Cu}-\mathrm{Cl}$ than previously reported with higher steam to copper chloride ratios.

In this paper, the steam requirement of the hydrolysis reaction was investigated in terms of the reaction quotient. The hydrolysis reaction has competing rate limiting factors in the process, 
such as heat transfer, mass transfer, and chemical kinetics that can affect the reaction quotient by increasing the time requirement to reach equilibrium. In Figs. 17 and 20, the steam requirement initially reduces with time before reaching a minimum and gradually increasing. The cumulative effects of mass transfer between the gas and solid reactants are likely the major factor causing the initial reduction. In Figs. 11, 17, and 20, the steady rise in steam requirement suggests that physical resistances to the reaction are developing [11], likely a crust of $\mathrm{Cu}_{2} \mathrm{OCl}_{2}$ is forming on the outside of the $\mathrm{CuCl}_{2}$ particles, creating resistances in the reactor. In these experiments, thermal equilibrium is attained before the reaction is initiated. Furthermore, a large amount of thermal energy is contained in the reactor vessel and furnace, compared to a small quantity of solid reactant, thus heat transfer is likely not a rate limiting factor in these experiments. However, small differences in the preheating parameters for each experiment can affect the results, such as the small differences in the chlorine production response time. The high steam conversion achieved in this paper, with the small contact time $(<0.5 \mathrm{~s})$ between the solid $\left(\mathrm{CuCl}_{2}\right)$ and gas $\left(\mathrm{H}_{2} \mathrm{O}\right)$ reactants, caused by the small quantity of $\mathrm{CuCl}_{2}$, suggest that chemical kinetics are not the rate limiting factor in these experiments.

\section{Conclusions}

In this paper, new experimental data was presented for the hydrolysis of humidified nitrogen in a vertical reactor with solid $\mathrm{CuCl}_{2}$ particles. Promising results were achieved, whereby the steam requirement can be reduced to between 3 and 0.5 (molar), with minimal chlorine

production. It suggests that the hydrolysis reactor can achieve conversion efficiencies to supply the necessary $\mathrm{HCl} / \mathrm{H}_{2} \mathrm{O}$ concentration to the electrolyzer without an $\mathrm{HCl} / \mathrm{H}_{2} \mathrm{O}$ concentrating process. This is a significant breakthrough in the development of the $\mathrm{Cu}-\mathrm{Cl}$ cycle, as it eliminates an energy intensive process of separating $\mathrm{HCl}$ gas and steam. These results benefit the system's ability to scale-up and integrate with other steps of the $\mathrm{Cu}-\mathrm{Cl}$ cycle, while providing a more competitive process of hydrogen production relative to other technologies, in terms of economic and environmental concerns.

\section{Acknowledgements}


Financial support from the Ontario Research Excellence Fund and Canada Research Chairs (CRC) program, as well as Atomice Energy of Canada Limited (AECL), is gratefully acknowledged.

\section{References}

[1] Lewis, M. A. and Masin, J. G. The evaluation of alternative thermochemical cycles - Part II: the down selection process. International journal of hydrogen energy 34, pp. 4125-4135, 2009.

[2] Andress, R. J., Huang, X., Bequette, B. W. and Martin, L. L. A systematic method for the evaluation of alternative thermochemical cycles for hydrogen production. International journal of hydrogen energy 34, pp. 4146-4154, 2009.

[3] Naterer, G. F. et al. Recent Canadian advances in nuclear-based hydrogen production. International journal of hydrogen energy 34, pp. 2901-2917, 2009.

[4] Naterer, G. F. et al. Canada's program on nuclear hydrogen production and the $\mathrm{Cu}-\mathrm{Cl}$ thermochemical cycle. Internation journal of hydrogen energy 35, pp. 10905-10926, 2010.

[5] Naterer, G. F. et al. Clean hydrogen production with the $\mathrm{Cu}-\mathrm{Cl}$ cycle - Progress of international consortium, I: Experimental unit operations. International journal of hydrogen energy 36, pp. 15472-15485, 2011.

[6] Marin, G. D., Wang, Z. L., Naterer, G. F., Gabriel, K. S. Byproducts and reaction pathways for integration of the $\mathrm{Cu}-\mathrm{Cl}$ cycle of hydrogen production. International journal of hydrogen energy 36, pp. 13414-24, 2011.

[7] Balashov V. N., Schatz, R., Chalkova, E., Akinfiev, N. N., Fedkin, M. V., Lvov, S. N. CuCl electrolysis for hydrogen production in the $\mathrm{Cu}-\mathrm{Cl}$ thermochemical cycle. Journal of the electrochemical society 158(3), pp. 266-275, 2011.

[8] Ferrandon, M. S. et al. Hydrogen production by the $\mathrm{Cu}-\mathrm{Cl}$ thermochemical cycle: Investigation of the key step of hydrolysing $\mathrm{CuCl}_{2}$ to $\mathrm{Cu}_{2} \mathrm{OCl}_{2}$ and $\mathrm{HCl}$ using a spray reactor. International journal hydrogen energy 35(3), pp. 992-1000, 2010. 
[9] Ferrandon, M., Lewis, M., Alvarez, F. and Shafirovich, E. Hydrolysis of $\mathrm{CuCl}_{2}$ in the $\mathrm{Cu}-\mathrm{Cl}$ thermochemical cycle for hydrogen production: experimental studies usiniug a spray reactor with an ultrasonic atomizer. International journal of hydrogen energy 35, pp. 1895-1904, 2010.

[10] Daggupati, V. N., Naterer, G. F., Gabriel, K. S., Gravelsins R. J. and Wang, Z. L. Solid particle decomposition and hydrolysis reaction kinetics in $\mathrm{Cu}-\mathrm{Cl}$ thermochemical hydrogen production. International journal of hydrogen energy 35(10), pp. 4877-4882, 2010.

[11] Levenspiel O. Chemical Reaction Engineering. $3^{\text {rd }}$ ed., John Wiley and Sons, Inc; 1999.

[12] The Engineering Toolbox. Water Vapor and Saturation Pressure in Humid Air. engineeringtoolbox.com. Accessed on November 18, 2011

[13] Kunii, D. and Levenspiel, O. Fluidization engineering second edition. Newton, USA : Butterworth-Heinemann, 1991.

[14] Kline S. J., McClintock F. A. Policy on reporting uncertainties in experimental measurements and results. ASME Journal of Heat Transfer - Policy.

\section{Appendix - Experimental Errors and Measurement Uncertainties}

An uncertainty and measurement error analysis of the experimental results is presented in this Appendix. The analysis of the experimental results includes the apparatus and measurement techniques by considering the bias and precision errors, as well as the uncertainty propagation in the calculations. To calculate the uncertainty $(U)$ of the experimental results, the bias and precision error are combined by [14]

$$
U_{i}=\sqrt{B_{i}^{2}+P_{i}^{2}}
$$

where $B$ and $P$ represent the bias and precision errors, respectively. The measuring devices in the experiments have a relatively high accuracy and low bias error associated with their operation (Table A1). These are used to calculate the propagation of bias error for the calculated variables (Table A2) with Eqs. (A2) - (A6). The relative bias error is taken as the ratio of bias error to the corresponding reference value, 


$$
\begin{aligned}
& B_{\dot{N}_{C l_{2}}}{ }^{2}=\dot{N}_{C l_{2}}{ }^{2}\left(\frac{B_{\dot{N}_{N_{2}}}^{2}}{\dot{N}_{N_{2}}}+\frac{B_{\dot{M}_{C l_{2}}}{ }^{2}}{\dot{M}_{C l_{2}}}\right) \\
& B_{\dot{N}_{H_{2} O, i n}}{ }^{2}=\dot{N}_{H_{2} O, \text { in }}{ }^{2}\left(3\left(\frac{B_{T_{H}}}{T_{H}}\right)^{2}+\left(\frac{B_{R H}}{R H}\right)^{2}+\left(\frac{B_{\dot{N}_{N_{2}}}}{\dot{N}_{N_{2}}}\right)^{2}\right) \\
& B_{\dot{N}_{H C l, \text { out }}}^{2}=\dot{N}_{H C l, \text { out }}{ }^{2}\left(\left(\frac{B_{\dot{M}_{C l_{2}}}}{\dot{M}_{C l_{2}}}\right)^{2}+\left(\frac{B_{V_{s}}}{V_{S}}\right)^{2}+\left(\frac{B_{t}}{t}\right)^{2}+2\left(\frac{B_{\dot{N}_{C l_{2}}}}{\dot{N}_{C l_{2}}}\right)^{2}\right) \\
& B_{\xi}^{2}=\dot{N}_{\xi}^{2}\left(\left(\frac{B_{\dot{N}_{H_{2} O \text { oin }}}}{\dot{N}_{H_{2} O, \text { in }}}\right)^{2}+\left(\frac{B_{\dot{N}_{H c l, o u t}}}{\dot{N}_{H c l, \text { out }}}\right)^{2}\right) \\
& B_{Q_{R}}{ }^{2}=Q_{R}^{2}\left(2\left(\frac{B_{\dot{N}_{H c l, o u t}}}{\dot{N}_{H c l, o u t}}\right)^{2}+\left(\frac{B_{\dot{N}_{H_{2} O} \text { out }}}{\dot{N}_{H_{2} O, \text { out }}}\right)^{2}\right)
\end{aligned}
$$

where the individual variables are defined in the nomenclature.

A sample of 50 measurements at equilibrium conditions is considered for the precision error calculations. Automatic measurements are recorded every 1.6 seconds, thus a sample of 50 measurements can be obtained in $80 \mathrm{~s}$ (Table A1). It is taken as double the standard deviation of the results [14]. The propagation of precision error is determined with Eqs. (A7) - (A11). As presented in Table A2, the net overall uncertainty, $\mathrm{U}$, is $\pm 10 \%$ for the reaction quotient of the hydrolysis reactor experiments.

$$
\begin{aligned}
& P_{\dot{N}_{C l_{2}}}{ }^{2}=\dot{N}_{C l_{2}}{ }^{2}\left(\left(\frac{P_{\dot{N}_{N_{2}}}}{\dot{N}_{N_{2}}}\right)^{2}+\left(\frac{P_{\dot{M}_{C l_{2}}}}{\dot{M}_{C l_{2}}}\right)^{2}\right) \\
& P_{\dot{N}_{H_{2} O \text {, in }}}{ }^{2}=\dot{N}_{H_{2} \text { O,in }}{ }^{2}\left(3\left(\frac{P_{T_{H}}}{T_{H}}\right)^{2}+\left(\frac{P_{R H}}{R H}\right)^{2}+\left(\frac{P_{\dot{N}_{N_{2}}}}{\dot{N}_{N_{2}}}\right)^{2}\right) \\
& P_{\dot{N}_{H C l, o u t}}{ }^{2}=\dot{N}_{H C l, \text { out }}{ }^{2}\left(\left(\frac{P_{\dot{M}_{C l_{2}}}}{\dot{M}_{C l_{2}}}\right)^{2}+\left(\frac{P_{V_{s}}}{V_{S}}\right)^{2}+\left(\frac{P_{t}}{t}\right)^{2}+2\left(\frac{P_{\dot{N}_{C l_{2}}}}{\dot{N}_{C l_{2}}}\right)^{2}\right)
\end{aligned}
$$




$$
\begin{aligned}
& P_{\xi}^{2}=\dot{N}_{\xi}^{2}\left(\left(\frac{P_{\dot{N}_{H_{2} O, i n}}}{\dot{N}_{H_{2} O, \text { in }}}\right)^{2}+\left(\frac{P_{\dot{N}_{H c l, o u t}}}{\dot{N}_{H c l, o u t}}\right)^{2}\right) \\
& P_{Q_{R}}{ }^{2}=Q_{R}{ }^{2}\left(\left(\frac{P_{\dot{N}_{H_{2} \text { O out }}}}{\dot{N}_{\mathrm{H}_{2} \mathrm{O}, \text { out }}}\right)^{2}+2\left(\frac{P_{\dot{N}_{\text {Hcl,out }}}}{\dot{N}_{\text {Hcl,out }}}\right)^{2}\right)
\end{aligned}
$$

Table 1: Experimental parameters with packed bed reactor connected to a humidifier

\begin{tabular}{|c|c|c|c|}
\hline Experiment & Temperature $\left.\mathbf{(}^{\circ} \mathbf{C}\right)$ & $\begin{array}{c}\text { Volume of } \mathbf{C u C l} \mathbf{2} \\
(\mathbf{m l})\end{array}$ & $\mathbf{H}_{2} \mathbf{O}$ density $\left(\mathbf{g} / \mathbf{m}^{\mathbf{3}} \mathbf{)}\right.$ \\
\hline 1 & 400 & 100 & 17.38 \\
\hline 2 & 365 & 100 & 16.38 \\
\hline 3 & 390 & 100 & 17.26 \\
\hline 4 & 390 & 450 & 17.42 \\
\hline
\end{tabular}


Table 2: Parameter for minimum fluidization velocity in experiments with the humidifier

\begin{tabular}{|c|c|}
\hline Variable & Value \\
\hline $\mathrm{D}_{\mathrm{p}}$ & $265 \mu \mathrm{m}$ \\
$\rho_{s}$ & $3390 \mathrm{~kg} / \mathrm{m}^{3}$ \\
$\rho_{v}$ & $1.251 \mathrm{~kg} / \mathrm{m}^{3}$ \\
$g$ & $9.81 \mathrm{~m} / \mathrm{s}^{2}$ \\
$\mu$ & $16.6 \mu \mathrm{Pa} \cdot \mathrm{s}$ \\
$\varepsilon$ & 0.6 \\
$\Phi$ & 1 \\
$\mathrm{~V}_{\mathrm{mf}}$ & $0.51 \mathrm{~m} / \mathrm{s}$ \\
\hline
\end{tabular}

Table 3: XRD results for solid products of hydrolysis with humidified nitrogen flow

\begin{tabular}{|c|c|c|c|}
\hline Test number & Temperature $\left[{ }^{\circ} \mathrm{C}\right]$ & Compound & $\begin{array}{c}\text { Similarity to diffraction } \\
\text { pattern [\%] }\end{array}$ \\
\hline \multirow{3}{*}{1} & \multirow{3}{*}{400} & $\mathrm{CuCl}_{2}$ & 7 \\
\hline & & $\mathrm{CuCl}$ & 46 \\
\hline & & $\mathrm{Cu}_{2} \mathrm{OCl}_{2}$ & - \\
\hline \multirow{3}{*}{2} & \multirow{3}{*}{365} & $\mathrm{CuCl}_{2}$ & 34 \\
\hline & & $\mathrm{CuCl}$ & 53 \\
\hline & & $\mathrm{Cu}_{2} \mathrm{OCl}_{2}$ & 2 \\
\hline \multirow{3}{*}{3} & \multirow{3}{*}{390} & $\mathrm{CuCl}_{2}$ & 37 \\
\hline & & $\mathrm{CuCl}$ & 6 \\
\hline & & $\mathrm{Cu}_{2} \mathrm{OCl}_{2}$ & 2 \\
\hline \multirow{3}{*}{4} & \multirow{3}{*}{390} & $\mathrm{CuCl}_{2}$ & 42 \\
\hline & & $\mathrm{CuCl}$ & 41 \\
\hline & & $\mathrm{Cu}_{2} \mathrm{OCl}_{2}$ & 2 \\
\hline
\end{tabular}


Table A1: Accuracy and relative error associated with the measurement devices

\begin{tabular}{|c|c|c|c|c|c|c|}
\hline Variable & Measurement device & Accuracy & $\begin{array}{l}\text { Device } \\
\text { range }\end{array}$ & $\begin{array}{l}\text { Reference } \\
\text { value }\end{array}$ & $\begin{array}{l}\text { Relative } \\
\text { bias error }\end{array}$ & $\begin{array}{l}\text { Relative } \\
\text { precision } \\
\text { error }\end{array}$ \\
\hline$\dot{N}_{N_{2}}$ & $\begin{array}{l}\text { Omega FVL-2600A } \\
\text { volumetric flow } \\
\text { controller }\end{array}$ & \pm 0.15 & $\begin{array}{l}0 \text { to } 50 \\
\text { LPM }\end{array}$ & $6 \mathrm{LPM}$ & 0.025 & $5.7 \times 10^{-9}$ \\
\hline$M_{C l_{2}}$ & $\begin{array}{l}\text { Optima continuous } \\
\text { gas analyzer AQ2020 }\end{array}$ & $\pm 0.025 \%$ & $\begin{array}{l}0 \text { to } \\
10 \%\end{array}$ & $10 \%$ & 0.0025 & 0.0024 \\
\hline$M_{C l}$ & $\begin{array}{l}\text { Geneq MKII chloride } \\
\text { analyzer } 926\end{array}$ & $\pm 3 \mathrm{mg} / \mathrm{l}$ & $\begin{array}{l}0 \text { to } \\
999 \\
\mathrm{mg} / \mathrm{l}\end{array}$ & $999 \mathrm{mg} / \mathrm{l}$ & 0.003 & 0.0081 \\
\hline$R H$ & $\begin{array}{l}\text { Hydroflex5-series } \\
\text { humidity transmitter }\end{array}$ & $\pm 0.08 \mathrm{RH}$ & $\begin{array}{l}0 \text { to } \\
100 \mathrm{RH}\end{array}$ & $98 \mathrm{RH}$ & 0.00082 & 0.0019 \\
\hline$T_{H}$ & $\begin{array}{l}\text { Hydroflex5-series } \\
\text { temperature } \\
\text { transmitter }\end{array}$ & $\pm 0.1^{\circ} \mathrm{C}$ & $\begin{array}{l}0 \text { to } \\
200^{\circ} \mathrm{C}\end{array}$ & $100^{\circ} \mathrm{C}$ & 0.001 & 0.01 \\
\hline V & $\begin{array}{l}\text { Eppendorf Research } \\
\text { plus pipette }\end{array}$ & $\pm 2 \mu 1$ & $\begin{array}{l}100 \text { to } \\
1000 \mu 1\end{array}$ & $500 \mu 1$ & 0.004 & - \\
\hline$M_{C u}$ & $\begin{array}{l}\text { Hach pocket } \\
\text { colorimeter II }\end{array}$ & $\begin{array}{ll} \pm & 0.04 \\
\mathrm{mg} / \mathrm{l} & \end{array}$ & $\begin{array}{l}0.04 \text { to } \\
5 \mathrm{mg} / \mathrm{l}\end{array}$ & $5 \mathrm{mg} / \mathrm{l}$ & 0.008 & - \\
\hline$t$ & $\begin{array}{l}\text { Fisher Scientific } \\
\text { traceable stopwatch }\end{array}$ & - & $300 \mathrm{~s}$ & $5 \mathrm{~s}$ & - & 0.011 \\
\hline$V_{s}$ & $\begin{array}{l}\text { Mettler Toledo } \\
\text { ML3002E }\end{array}$ & $\pm 0.01 \mathrm{~g}$ & $\begin{array}{l}100 \text { to } \\
3200 \mathrm{~g}\end{array}$ & $350 \mathrm{~g}$ & 0.000029 & - \\
\hline$T$ & $\begin{array}{l}\text { Omega Type-K } \\
\text { Thermocouple }\end{array}$ & $\pm 2.2^{\circ} \mathrm{C}$ & $\begin{array}{l}-200 \text { to } \\
1250^{\circ} \mathrm{C}\end{array}$ & $400^{\circ} \mathrm{C}$ & 0.0055 & 0.00063 \\
\hline$P$ & $\begin{array}{l}\text { Burkert Pressure } \\
\text { Transmitter } 8311\end{array}$ & \pm 0.04 bar & $\begin{array}{l}0 \text { to } 4 \\
\text { bar }\end{array}$ & $1.1 \mathrm{bar}$ & 0.033 & 0.026 \\
\hline$p H$ & $\begin{array}{l}\text { Omega PHH-103A } \\
\text { pH meter }\end{array}$ & $\pm 0.02 \mathrm{pH}$ & $\begin{array}{l}0 \text { to } 14 \\
\mathrm{pH}\end{array}$ & $14 \mathrm{pH}$ & 0.0014 & - \\
\hline
\end{tabular}


Table A2: Propagation of experimental uncertainty

\begin{tabular}{|c|l|l|l|l|}
\hline Variable & $\begin{array}{c}\text { Equation } \\
\text { numbers }\end{array}$ & $\begin{array}{c}\text { Bias } \\
\text { error }\end{array}$ & $\begin{array}{c}\text { Precision } \\
\text { error }\end{array}$ & Uncertainty \\
\hline$\dot{N}_{C l_{2}}$ & A2 and A7 & 0.025 & 0.003 & 0.029 \\
\hline$\dot{N}_{H_{2} O, \text { in }}$ & A3 and A8 & 0.025 & 0.017 & 0.043 \\
\hline$\dot{N}_{H C l, o u t}$ & A4 and A9 & 0.036 & 0.68 & 0.050 \\
\hline$\xi$ & A5 and A10 & 0.044 & 0.68 & 0.066 \\
\hline$Q_{R}$ & A6 and A11 & 0.067 & 0.030 & 0.097 \\
\hline
\end{tabular}




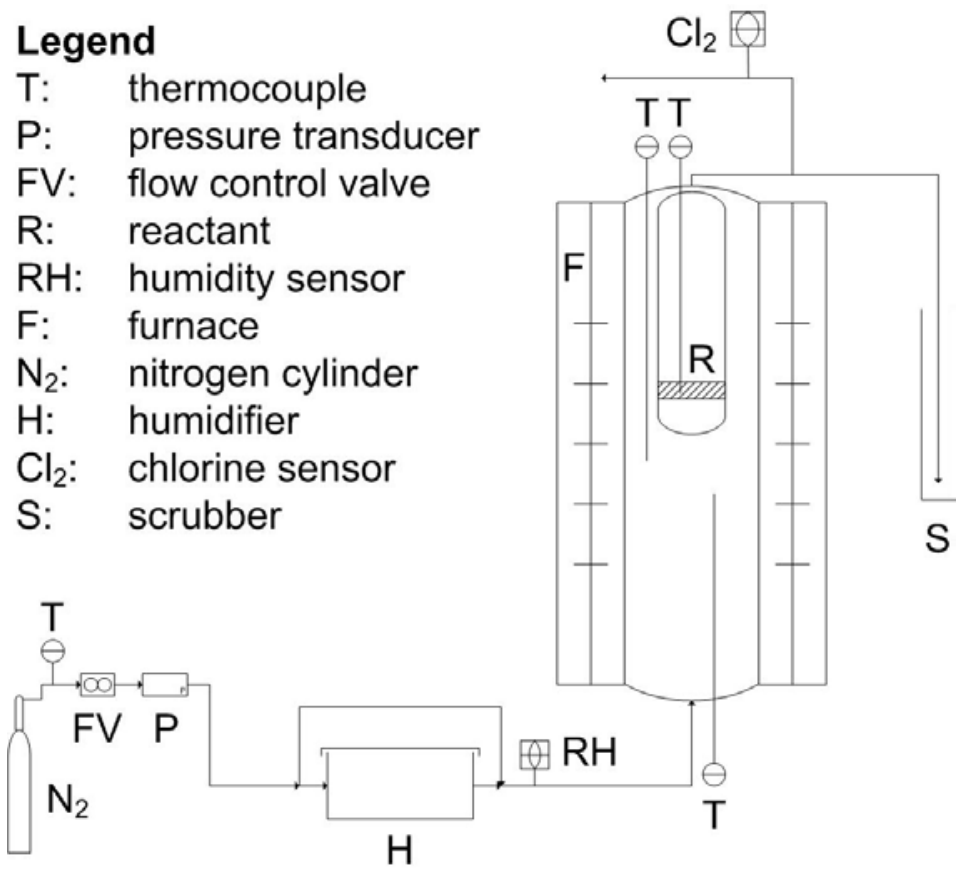

(a)

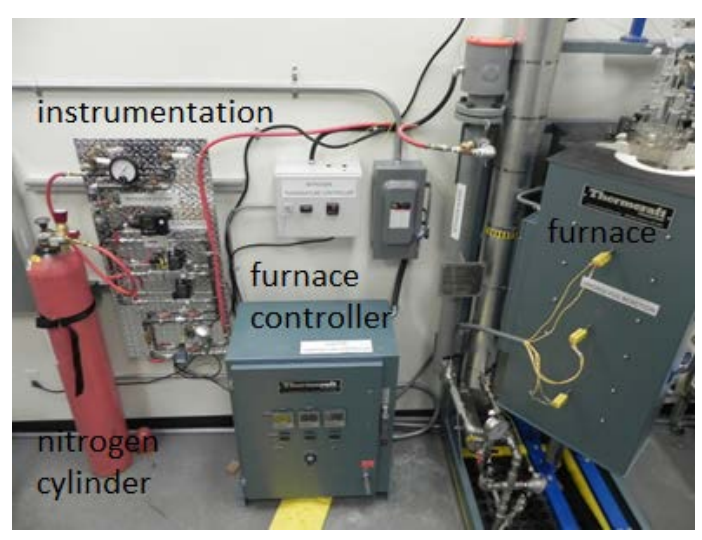

(b)

Figure 1: Experimental apparatus of the hydrolysis reactor: (a) schematic and (b) photograph 


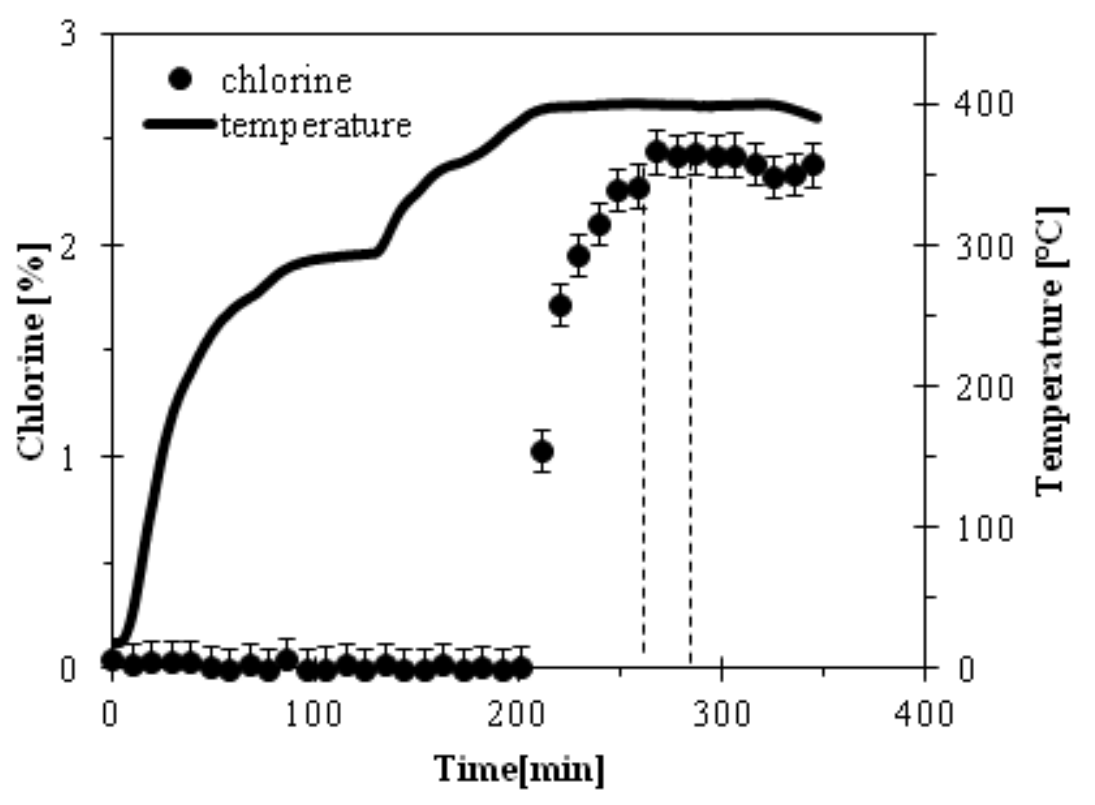

(a)

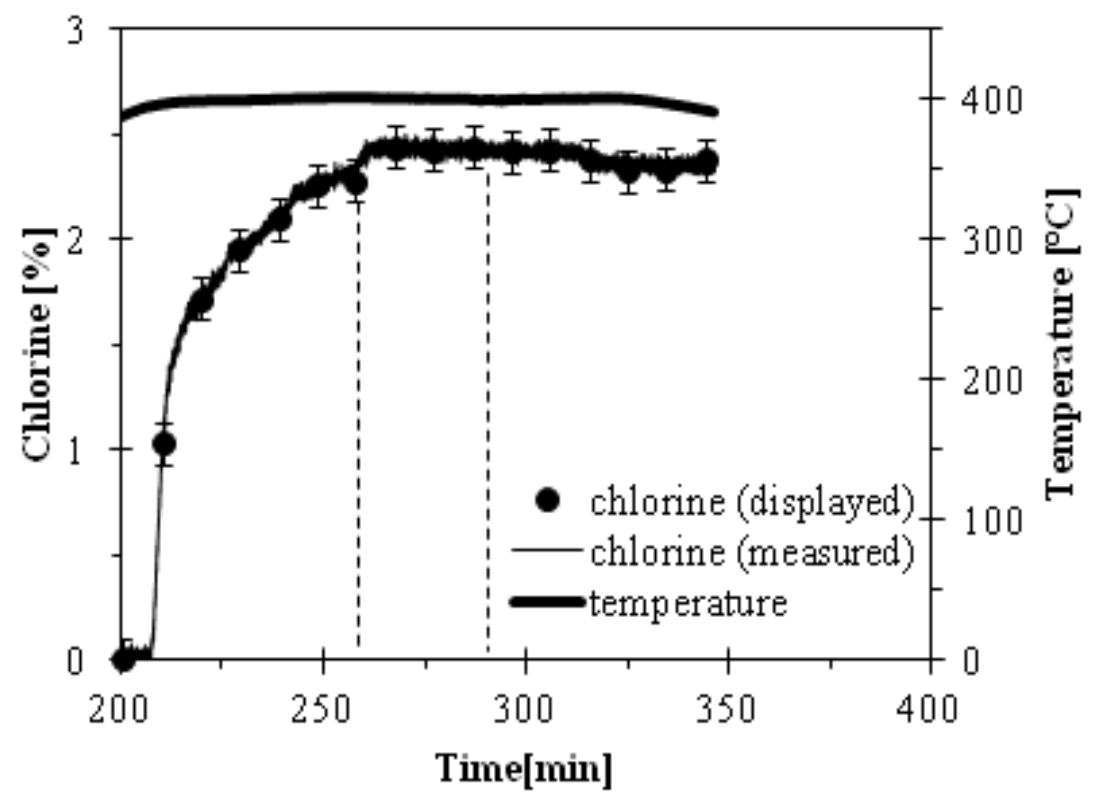

(b)

Figure 2: Chlorine production at $400^{\circ} \mathrm{C}$ with (a) preheating and (b) chlorine production 


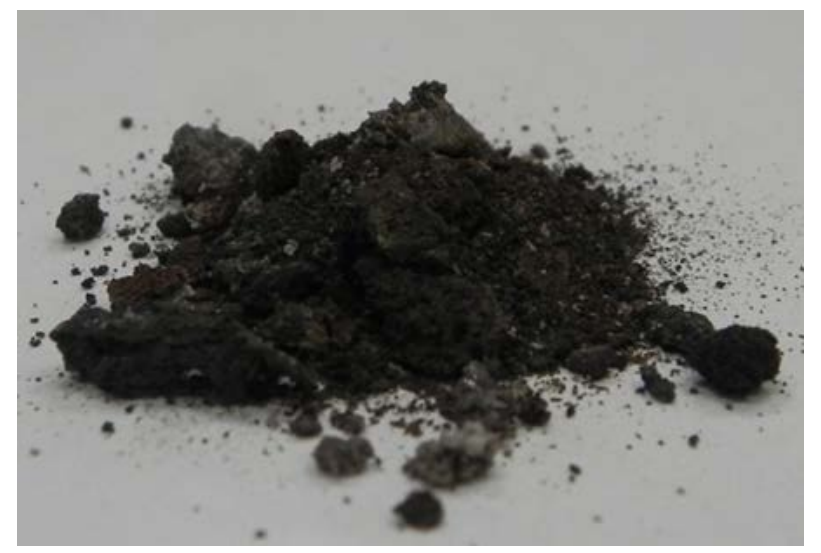

Figure 3: Solid products of hydrolysis reaction at $400^{\circ} \mathrm{C}$

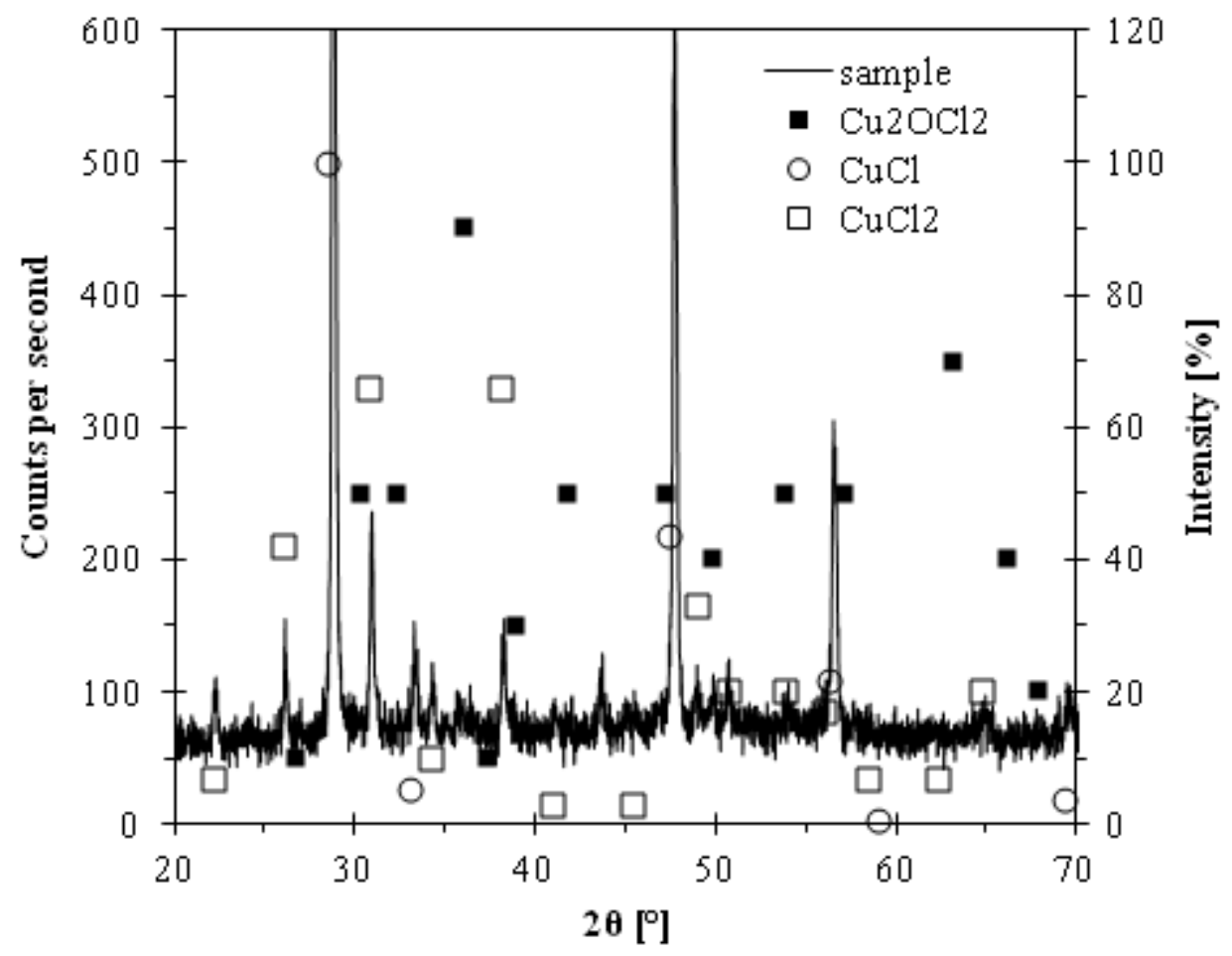

Figure 4: XRD pattern of solid products at $400^{\circ} \mathrm{C}$ 


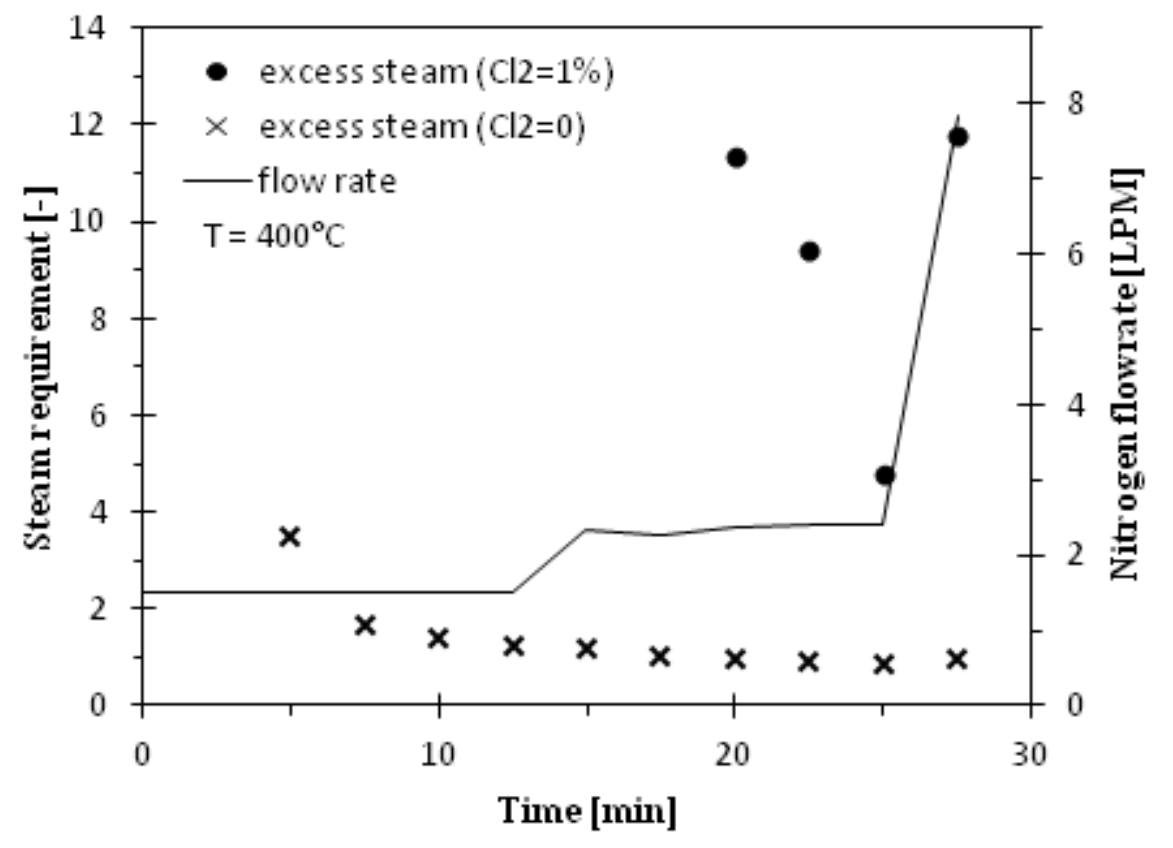

Figure 5: Transient steam requirement of the hydrolysis reaction at $400^{\circ} \mathrm{C}$

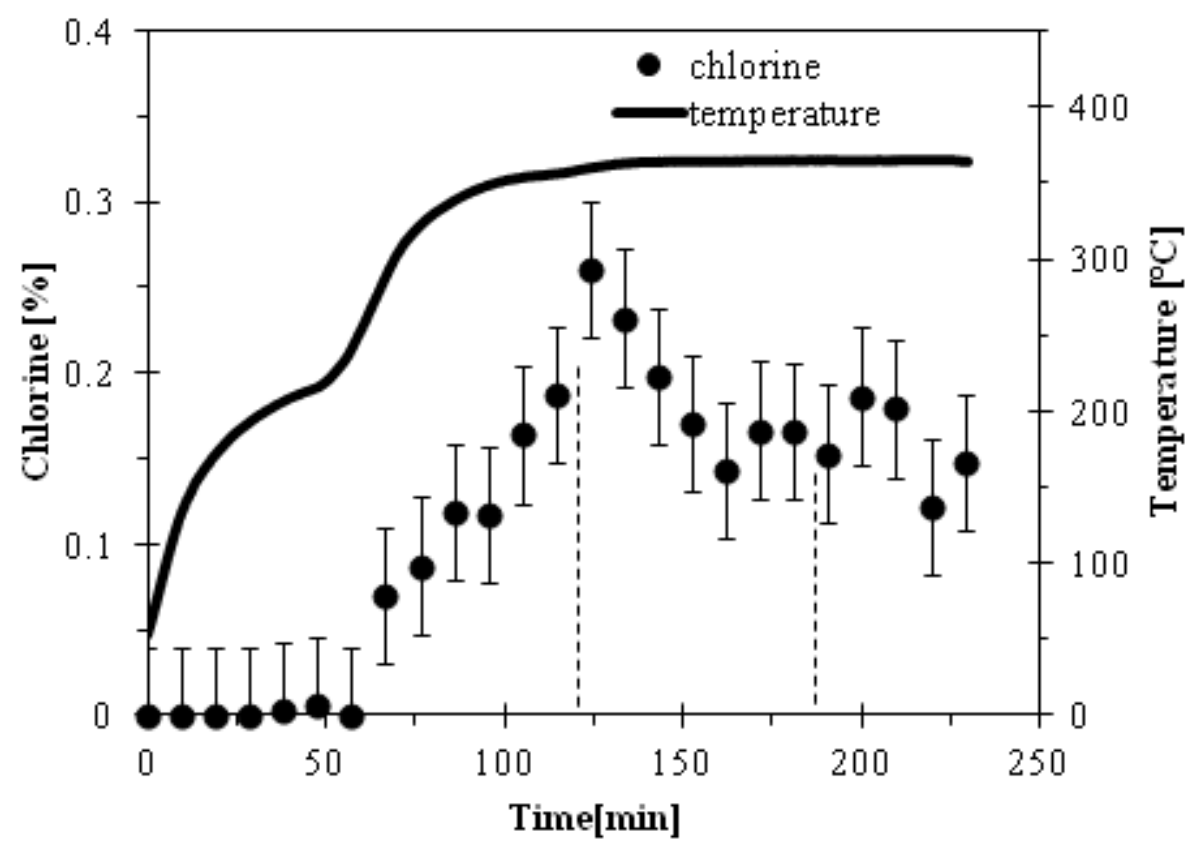

Figure 6: Chlorine production at $365^{\circ} \mathrm{C}$ with preheating 


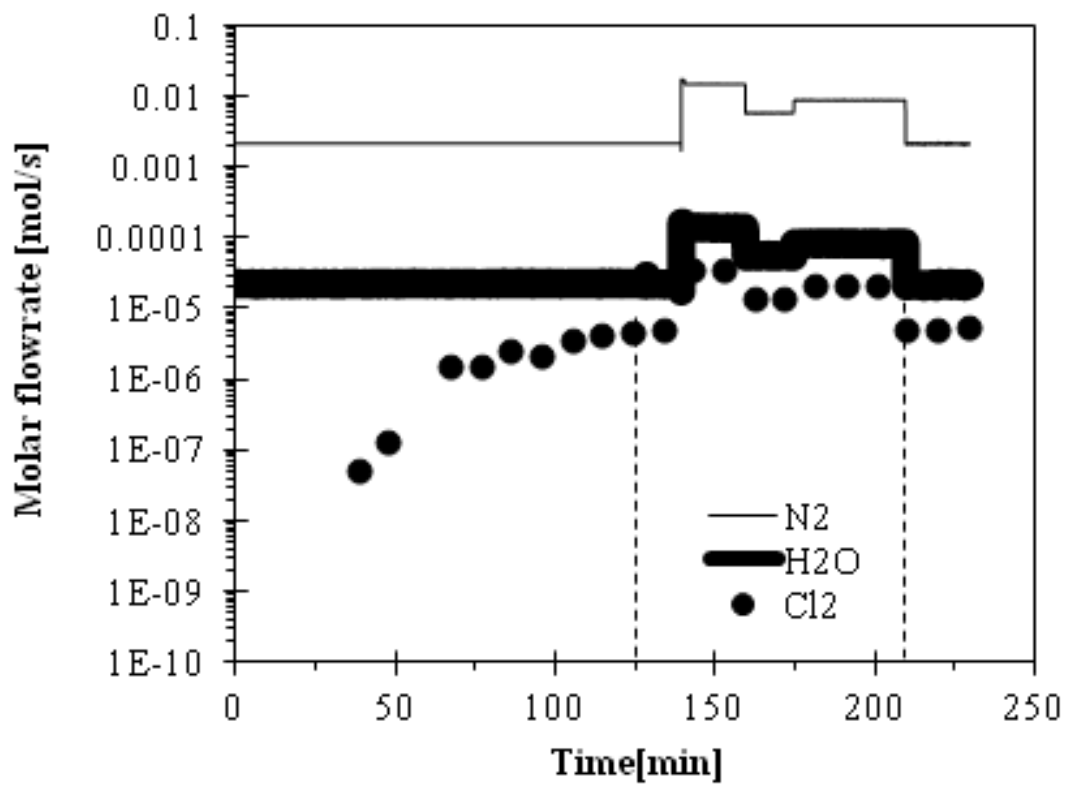

Figure 7: Molar flowrates of compounds in the hydrolysis reactor at $365^{\circ} \mathrm{C}$

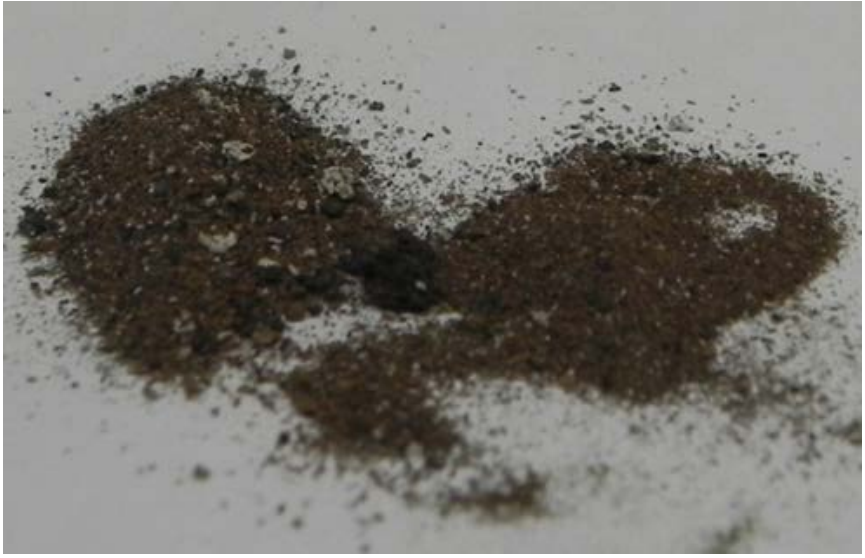

Figure 8: Solid products of hydrolysis reaction at $365^{\circ} \mathrm{C}$ 


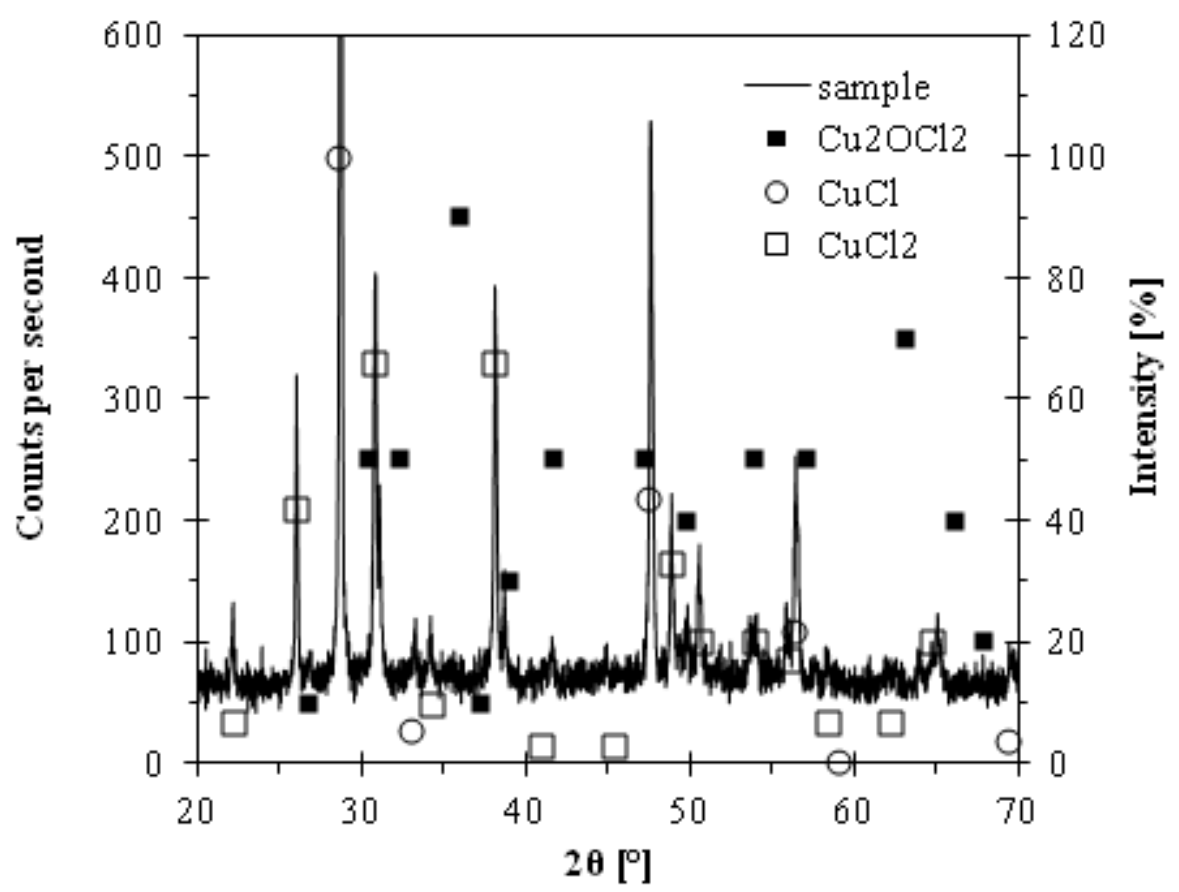

Figure 9: XRD data for hydrolysis solid products at $365^{\circ} \mathrm{C}$

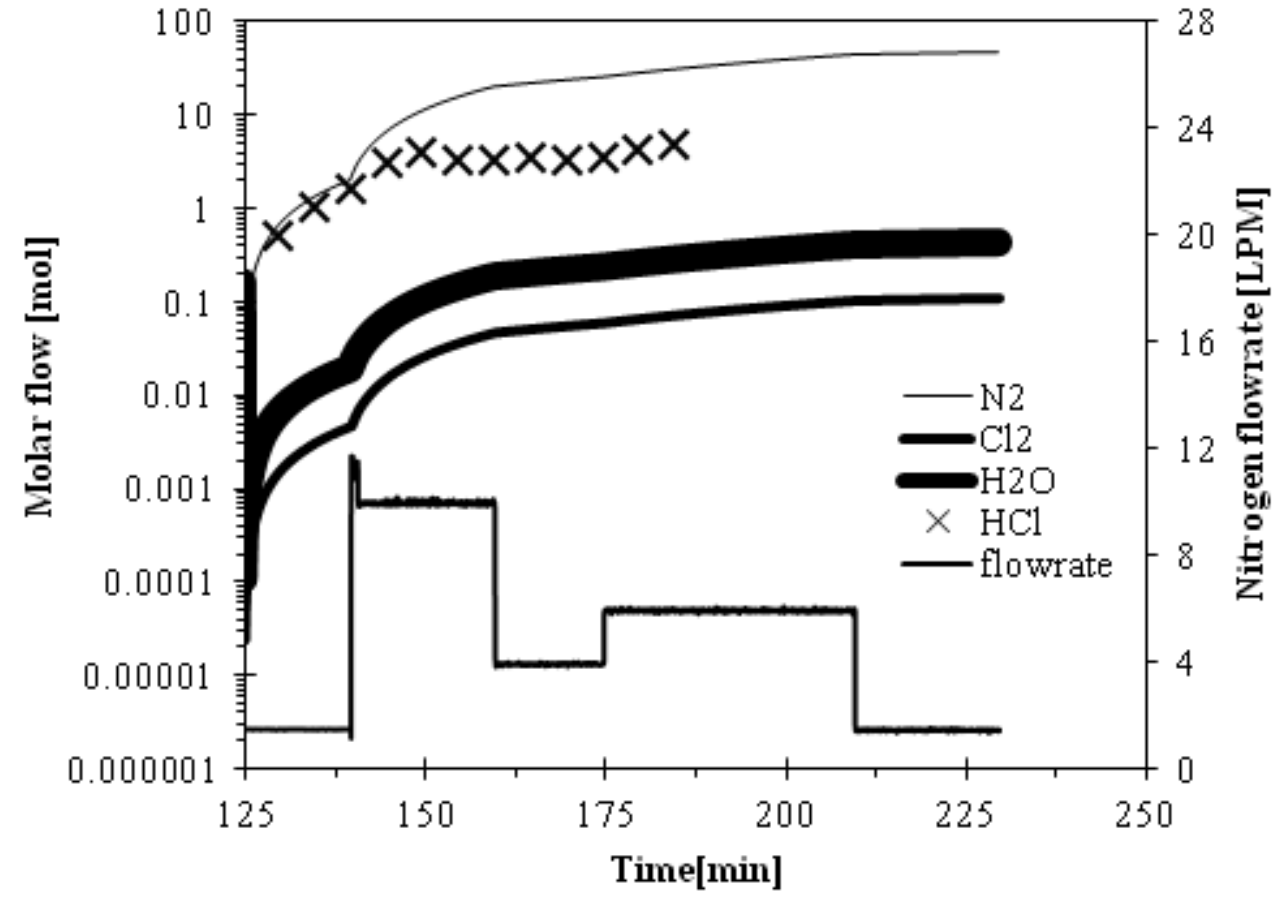

Figure 10: Cumulative molar flows of compounds in the hydrolysis reactor at $365^{\circ} \mathrm{C}$ 


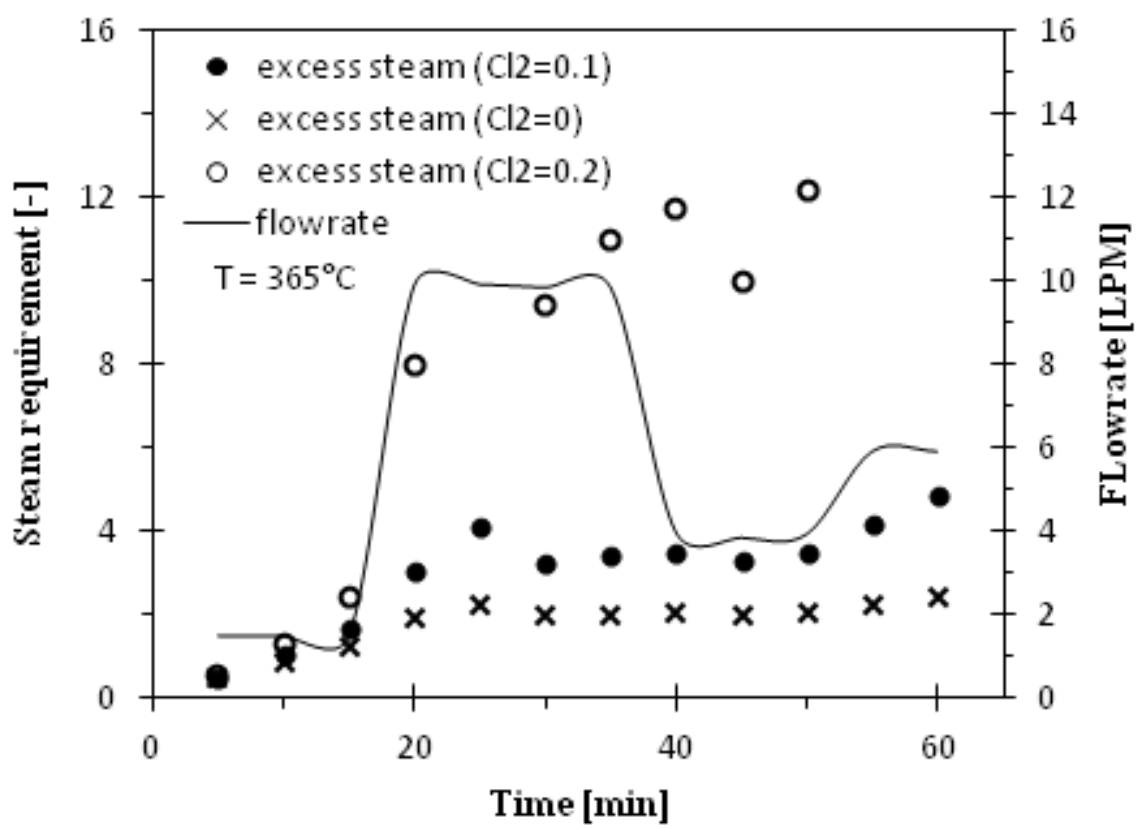

Figure 11: Transient steam requirement of the hydrolysis reaction at $365^{\circ} \mathrm{C}$

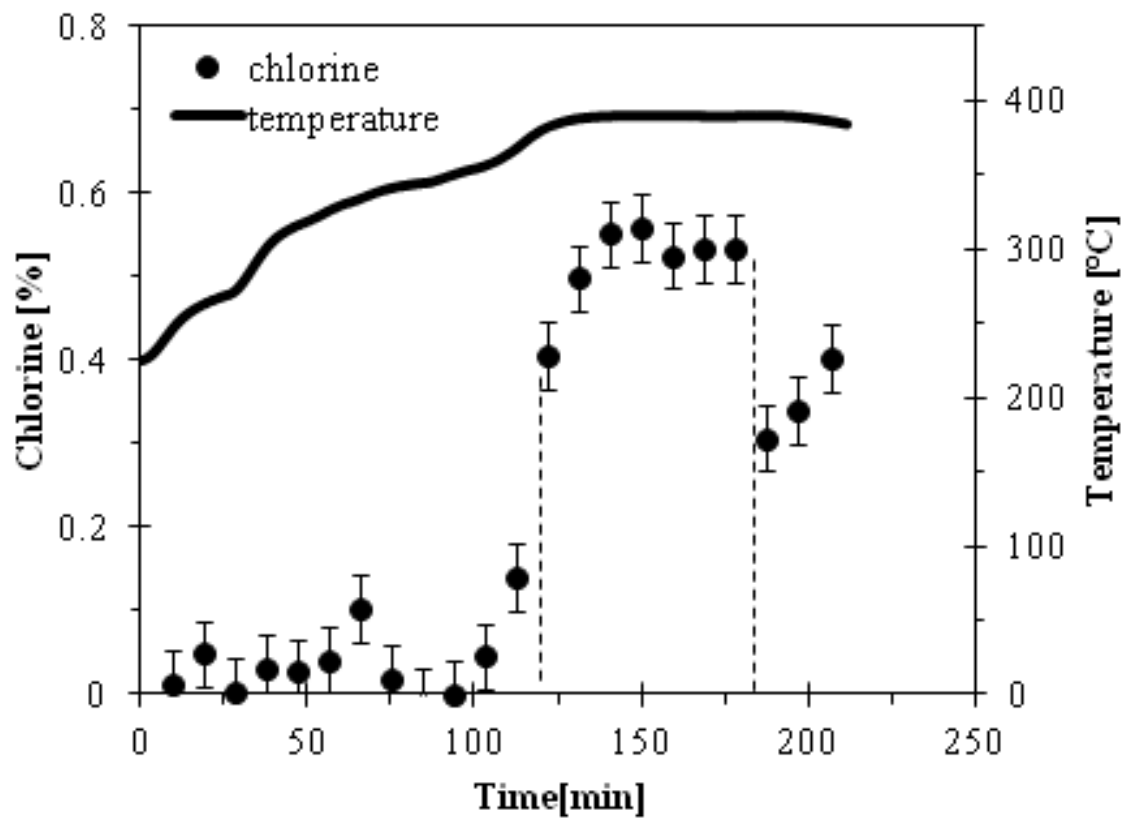

Figure 12: Chlorine production at $390^{\circ} \mathrm{C}$ with preheating 


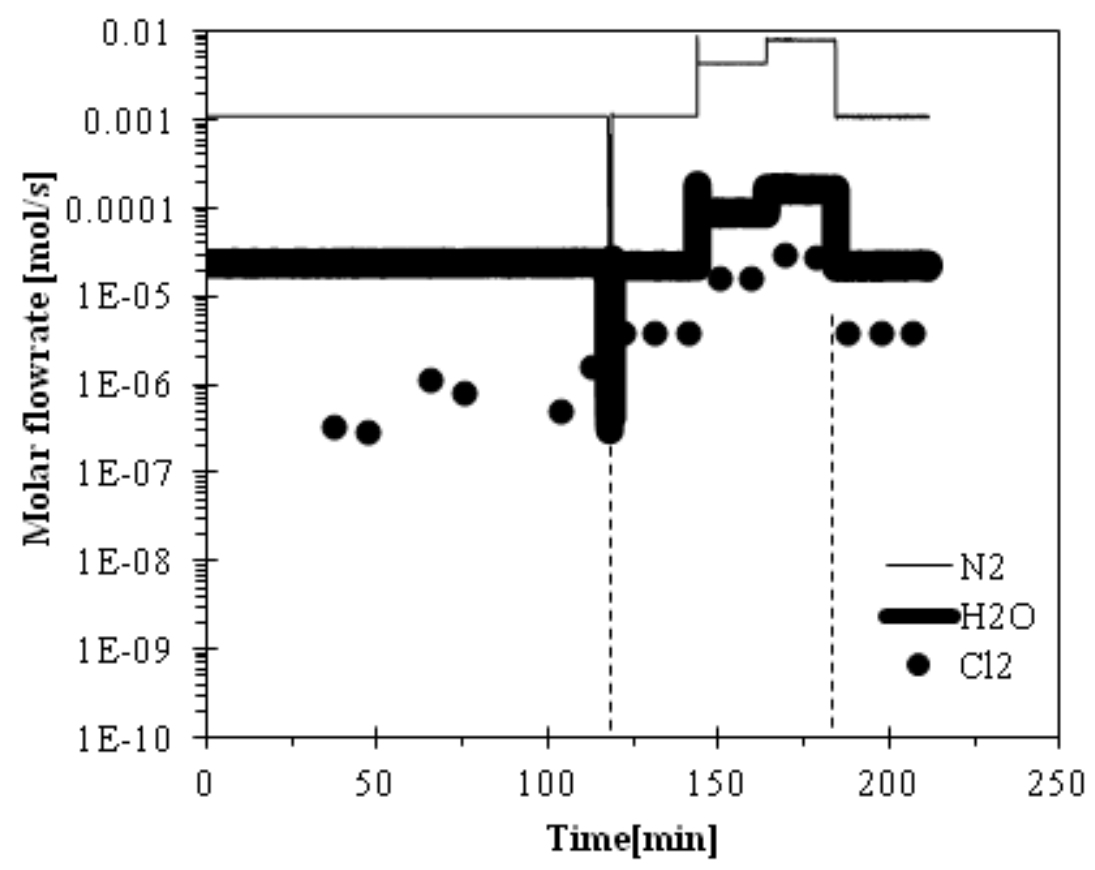

Figure 13: Molar flowrates of compounds in the hydrolysis reactor at $390^{\circ} \mathrm{C}$

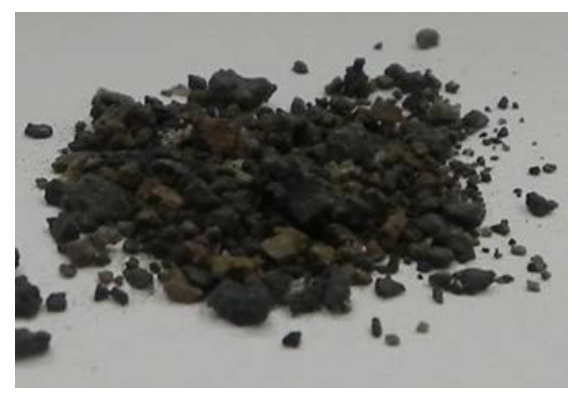

(a)

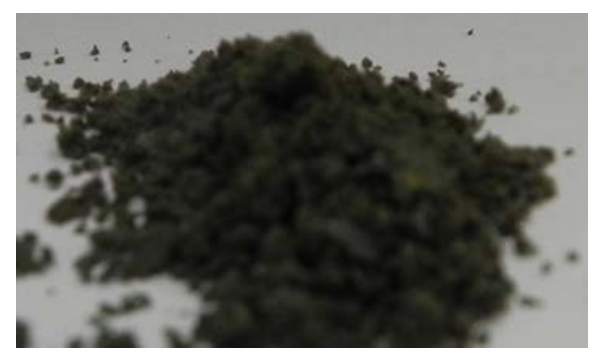

(b)

Figure 14: Solid products of hydrolysis reaction at $390^{\circ} \mathrm{C}$ from the reactant's (a) top surface, and (b) bottom surface 


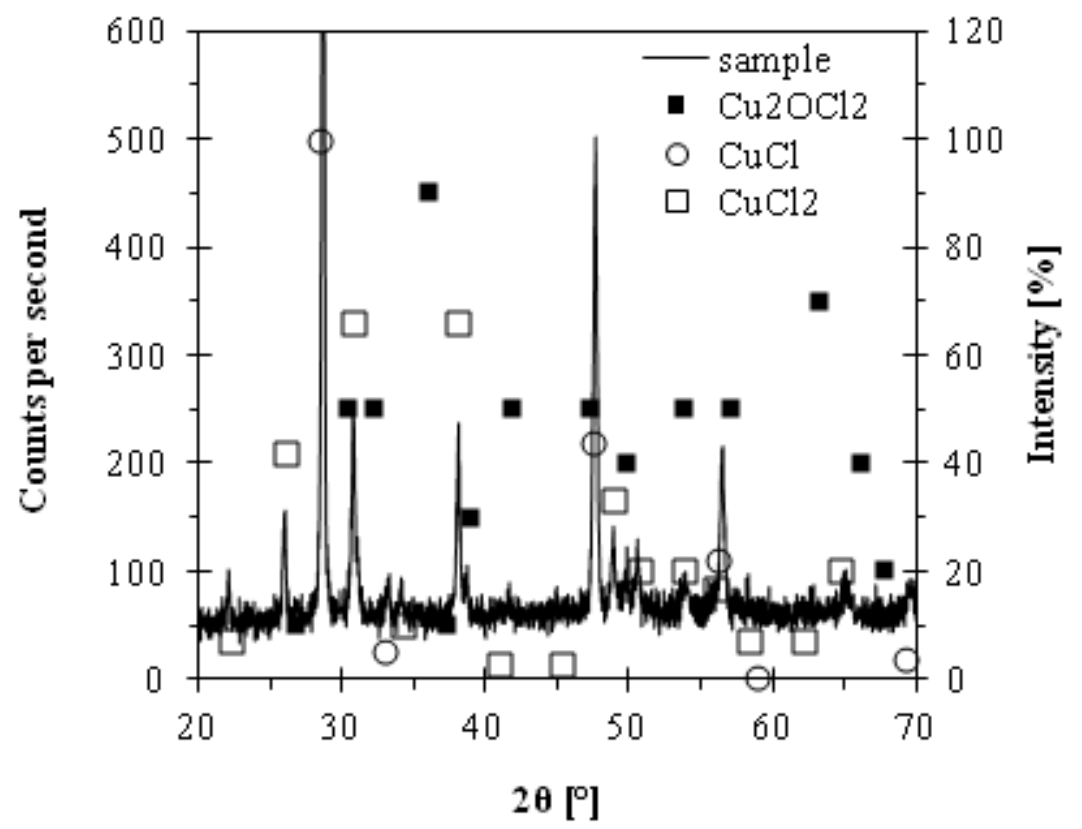

(a)

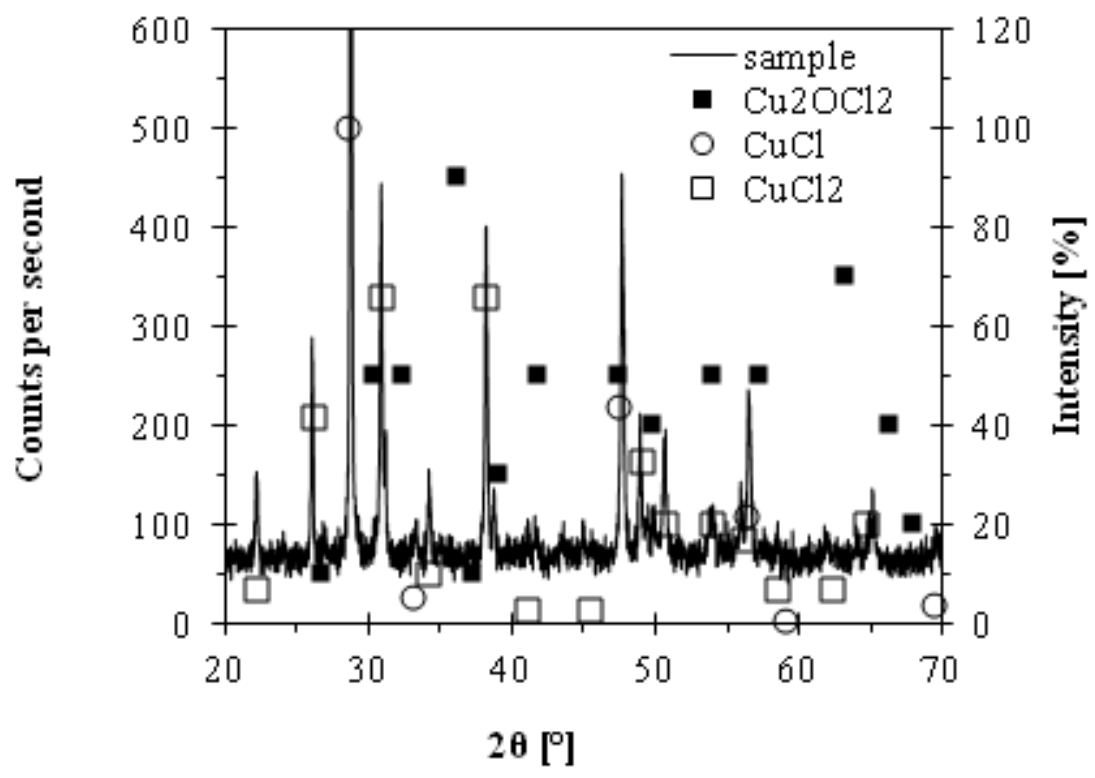

(b)

Figure 15: XRD results for hydrolysis solid products at $390^{\circ} \mathrm{C}$ from the reactant's (a) top surface and (b) bottom surface 


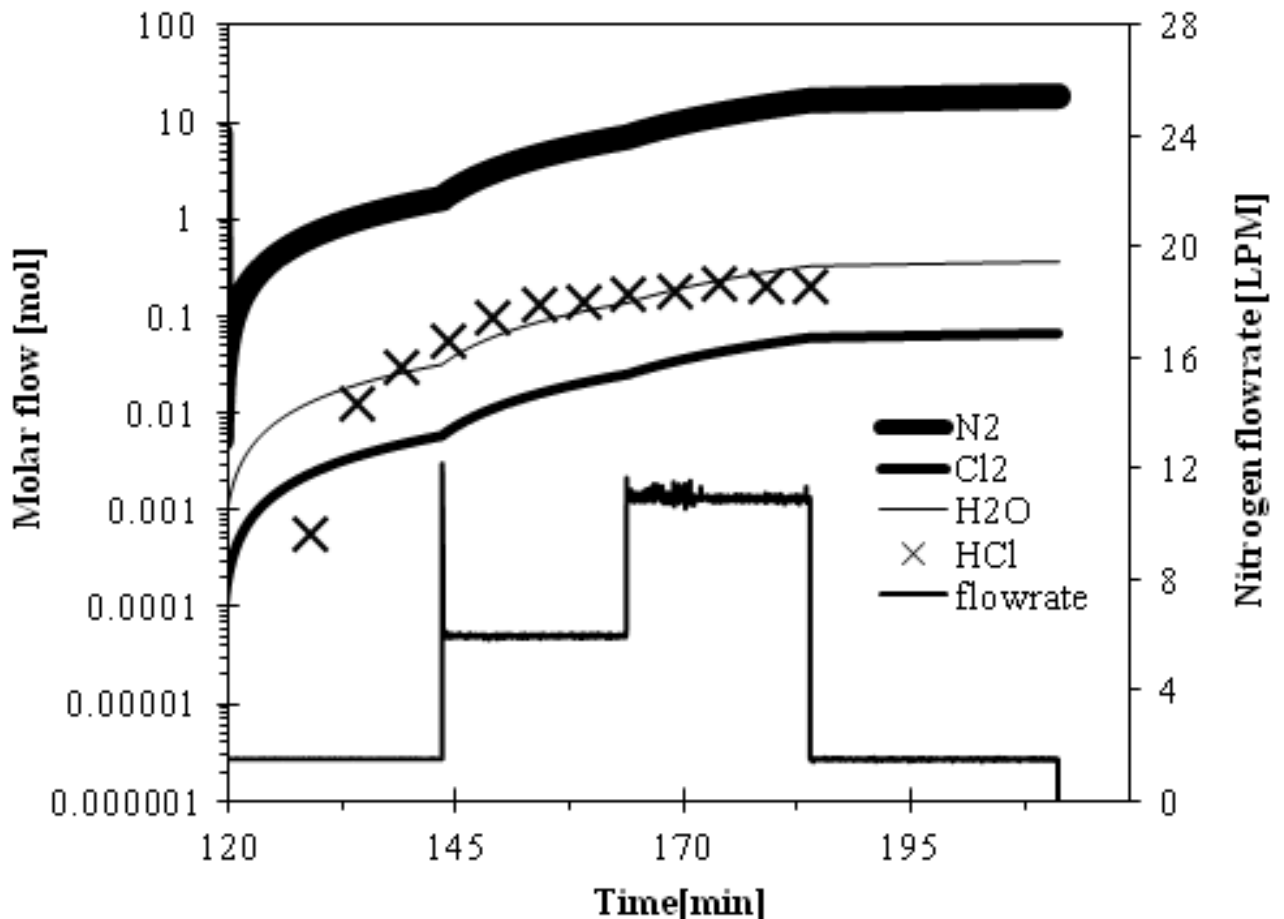

Figure 16: Cumulative molar flows of compounds in the hydrolysis reactor at $390^{\circ} \mathrm{C}$

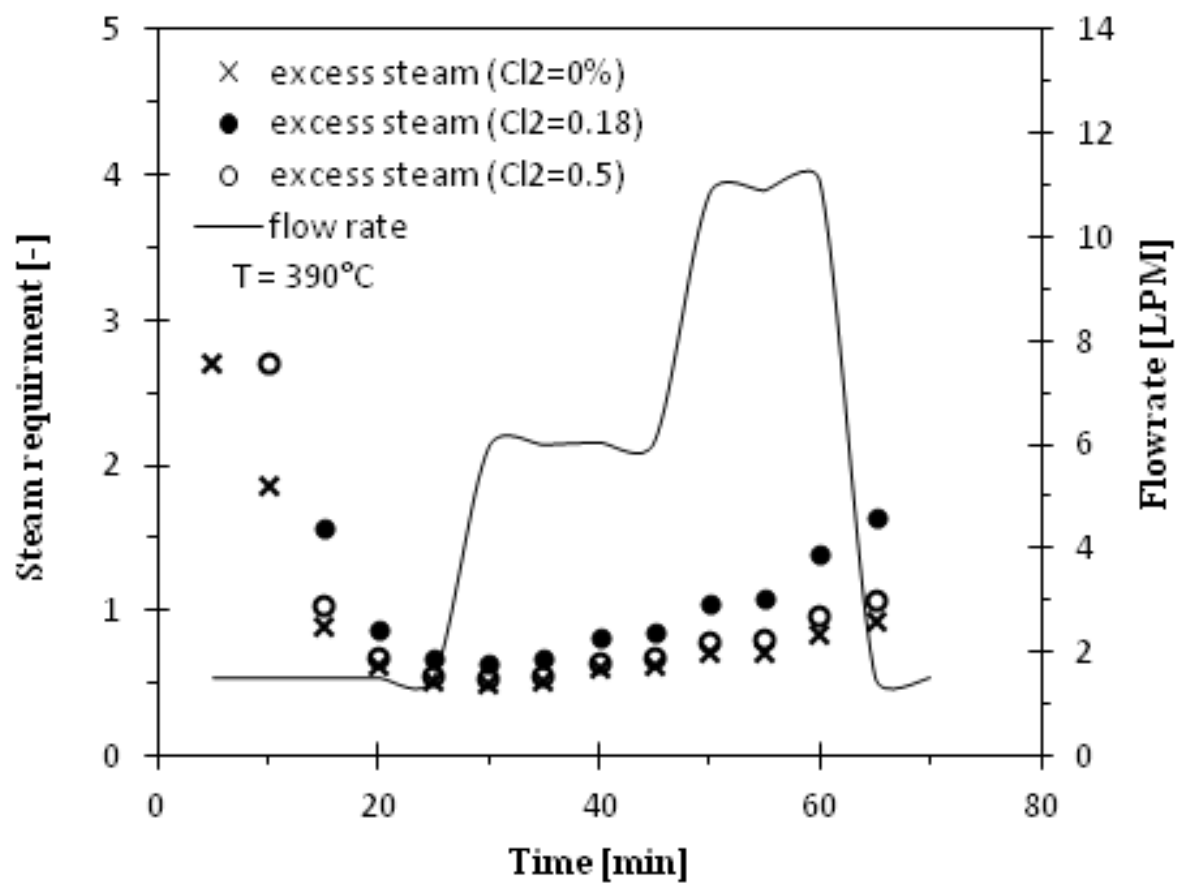

Figure 17: Transient steam requirement of the hydrolysis reaction at $390^{\circ} \mathrm{C}$ 


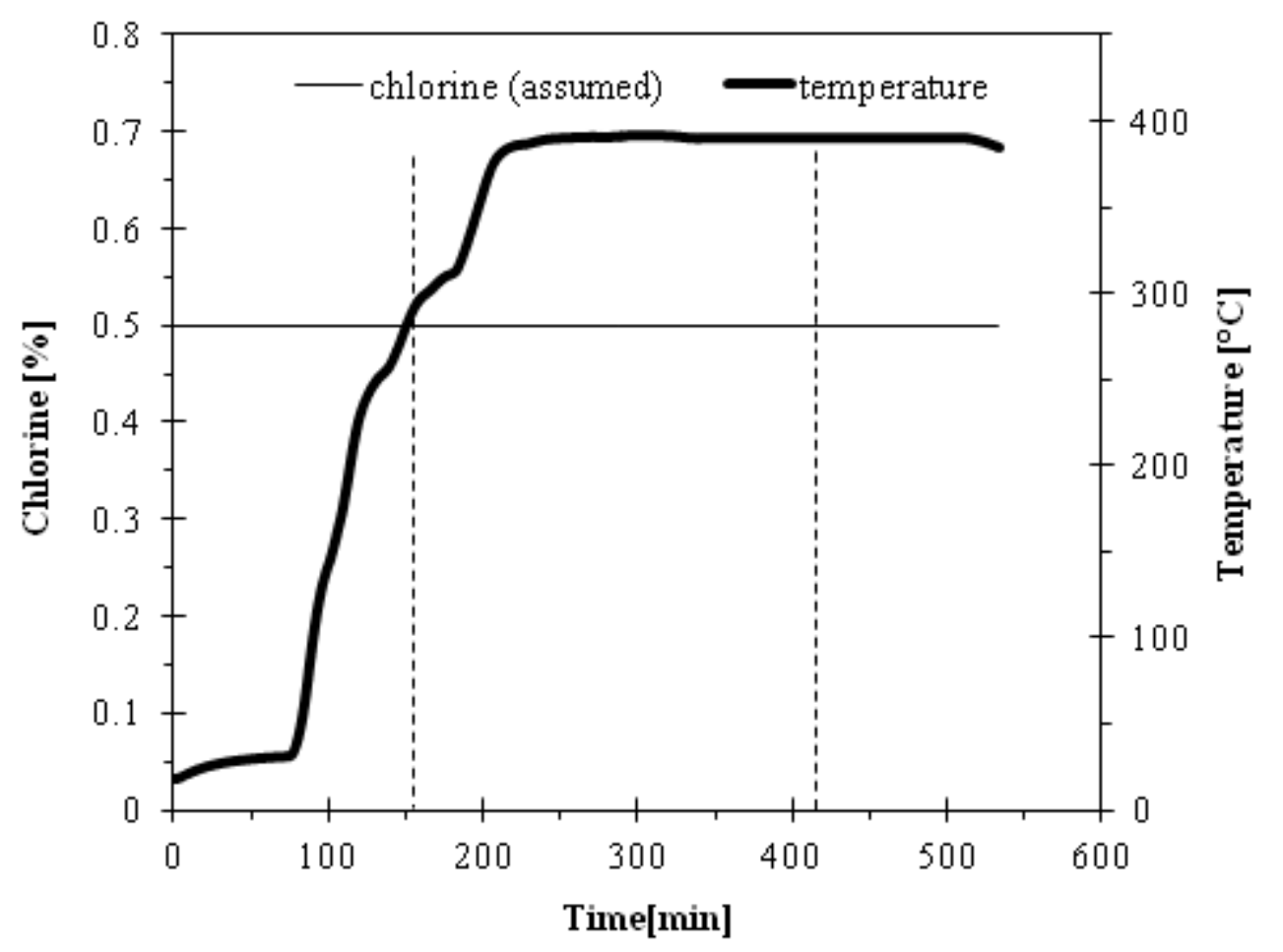

Figure 18: Preheating and reaction temperature of the hydrolysis reactor at $390^{\circ} \mathrm{C}$

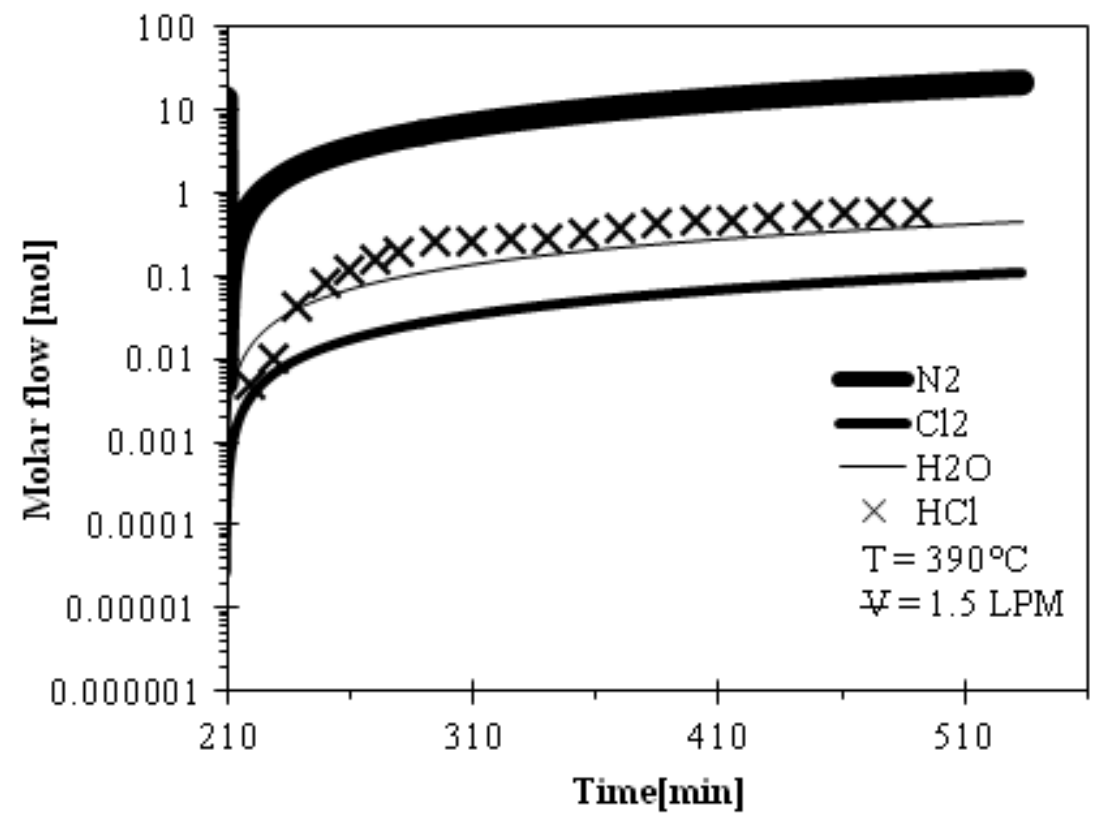

Figure 19: Cumulative molar flows of compounds in the hydrolysis reactor at $390^{\circ} \mathrm{C}$ 


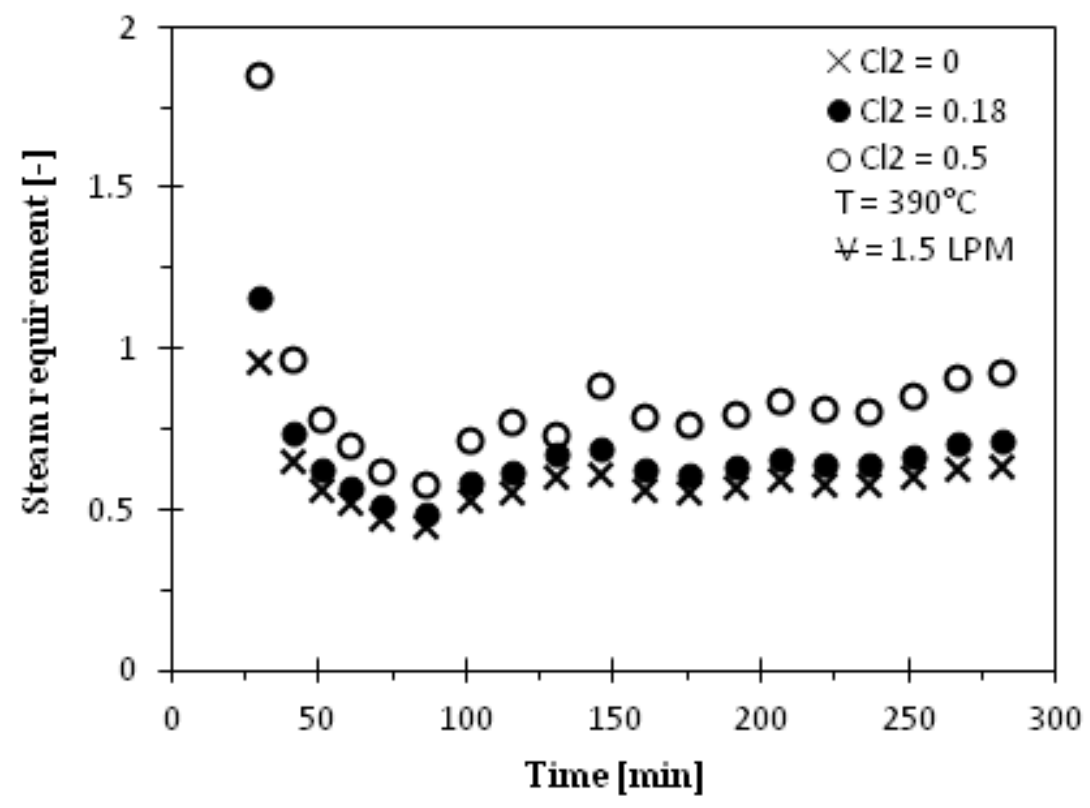

Figure 20: Validation of transient steam requirement of the hydrolysis reaction at $390^{\circ} \mathrm{C}$ 